\title{
The Physical Laws and Mathematical Axioms of the Brain's OS and the Traditional Fundamental Laws of Thought of Logic and Philosophy
}

\author{
Leo Depuydt \\ Department of Egyptology and Assyriology, Brown University, Providence, Rhode Island, USA \\ Email: depuydt@juno.com
}

How to cite this paper: Depuydt, L. (2021) The Physical Laws and Mathematical Axioms of the Brain's OS and the Traditional Fundamental Laws of Thought of Logic and Philosophy. Advances in Pure Mathematics, 11, 988-1039.

https://doi.org/10.4236/apm.2021.1112064

Received: August 23, 2021

Accepted: December 28, 2021

Published: December 31, 2021

Copyright $\odot 2021$ by author(s) and Scientific Research Publishing Inc. This work is licensed under the Creative Commons Attribution International License (CC BY 4.0).

http://creativecommons.org/licenses/by/4.0/

\begin{abstract}
This article presents four (4) additions to a book on the brain's OS published by SciRP in 2015 [1]. It is a kind of appendix to the book. Some familiarity with the earlier book is presupposed. The book itself proposes a complete physical and mathematical blueprint of the brain's OS. A first addition to the book (see Chapters 5 to 10 below) concerns the relation between the afore-mentioned blueprint and the more than 2000-year-old so-called fundamental laws of thought of logic and philosophy, which came to be viewed as being three (3) in number, namely the laws of 1) Identity, 2) Contradiction, and 3) the Excluded Middle. The blueprint and the laws cannot both be the final foundation of the brain's OS. The design of the present paper is to interpret the laws in strictly mathematical terms in light of the blueprint. This addition constitutes the bulk of the present article. Chapters 5 to 8 set the stage. Chapters 9 and 10 present a detailed mathematical analysis of the laws. A second addition to the book (Chapter 11) concerns the distinction between the laws and the axioms of the brain's OS. Laws are part of physics. Axioms are part of mathematics. Since the theory of the brain's OS involves both physics and mathematics, it exhibits both laws and axioms. A third addition (Chapter 12) to the book involves an additional flavor of digitality in the brain's OS. In the book, there are five (5). But brain chemistry requires a sixth. It will be called Existence Digitality. A fourth addition (Chapter 13) concerns reflections on the role of imagination in theories of physics in light of the ignorance of deeper causes. Chapters 1 to 4 present preliminary matter, for the most part a brief survey of general concepts derived from what is in the book [1]. Some historical notes are gathered at the end in Chapter 14.
\end{abstract}

\section{Keywords}

Aristotle, Boole, G., Brain's OS, Fundamental Laws of Thought, Kolmogorov, 
A. N., Laws and Axioms, Leibniz, G. W., Locke, J., Logic, Philosophy, Rational Human Intelligence, Venn, J.

\section{Introduction}

In a book published by SciRP in 2015, the present writer proposed a theory that is styled as the complete blueprint of rational human intelligence, the brain's OS (Operating System) [1]. It is a theory of physics with a digital mathematics mostly designed by G. Boole.

It is the blueprint of G. Boole's Cathedral. The blueprint is complete (except for a sixth flavor of digitality, see below). But the Cathedral still needs to be built. The theory is presented as the necessary foundation for-and the only path to-building an Artificial Intelligence that replicates rational human intelligence blow by blow.

The present article constitutes an appendix to this book. The book contains the general theoretical framework and the pertinent literature. Neither is repeated here. This appendix provides four (4) main additions.

A first addition concerns the relation between the blueprint and the more than 2000-year-old so-called fundamental laws of thought of logic and philosophy, going back to Aristotle and before. They came to be viewed as being three in number, the laws of 1) Identity (as in "A cow is a cow [and not not a cow]),"

2) Contradiction ("Something cannot be both a cow and not a cow"), and 3) the Excluded Middle ("Something is either a cow or not a cow"). The blueprint and the laws cannot both be fundamental at the same time. The design of the present paper is to interpret the laws in light of the blueprint. The traditional laws are not wrong. They are incomplete.

A second addition to the book is an additional flavor of digitality in the brain's OS. In the book, there are five (5). But there is need for a sixth. It will be called Existence Digitality. In this regard, J. Venn led the way. He dared to question the centuries-old traditional analysis of the so-called particular propositions of the type "Some A are B." In this regard, J. Venn went a step further than G. Boole in completely recasting Aristotelian logic.

A third addition concerns drawing a distinction between the laws and the axioms of the brain's OS. Laws are part of physics. Axioms are part of mathematics. Since the theory of the brain's OS involves both physics and mathematics, it exhibits both laws and axioms. Which are they respectively and how can one distinguish them?

A fourth addition concerns reflections on the role of imagination in theories of physics in light of the ignorance of deeper causes. As regards the physical theory of mass and motion, it is not really known what mass, time, and space are. They are measured and then related to one another. In the same way, the brain activity underlying the brain's OS is unknown for now. 


\section{Method}

The method of mathematical analysis used in what follows is for the most part G. Boole's digital algebra.

The traditional fundamental laws of thought belong to the realm of philosophy and logic. But they are discussed here in a mathematical journal because they present themselves as an alternative to the physical and mathematical theory of the brain's OS. The laws and the theory cannot both be fundamental. It is therefore necessary to propose a mathematical interpretation of the traditional laws of thought. In this manner, it becomes possible to establish the exact meaning and significance of the laws of thought.

The mathematics that is used in this article is G. Boole's digital algebra in his characteristic notation. G. Boole's work on logic and probability is in general poorly understood and for the most part disregarded. One often finds it met with incomprehension. It is a hurdle that the present article faces. Promoting G. Boole's theories is a bit of an uphill battle. One rises to the defense of something that many regard as something of a curiosity and that leaves some mystified. A heavy burden of proof rests on those who believe that G. Boole showed us the way to how we think rationally.

In the afore-mentioned book, an effort was made to present Boole's algebra from first principles. Repeating this procedure here would add too much to the length of the article.

\section{Framework (1): Physical and Mathematical Theory of Rational Human Intelligence, the Brain's OS}

\subsection{Rational Human Intelligence}

The twenty-first century will be the century of the human brain. The brain is so close and yet its precise workings seem so far.

There are so many things that the brain does for us. They may all be called intelligences. Each intelligence is something that the brain has taught itself to do through the body to which it is attached by means of the nervous system.

This article is concerned with one kind of intelligence, rational human intelligence, the brain's Operating System (OS).

Rational human intelligence is the only type of intelligence that needs to be the same in everyone's brain. Otherwise, we could not communicate with one another intelligibly. The brain's OS has to be the same in all of us. Each brain needs to be equipped with an exact same copy. It is mostly acquired in childhood as the brain engages reality around itself through the senses.

\subsection{Relation of the Brain's OS to All Other Forms of Intelligence and to Knowledge}

The brain exhibits many kinds of intelligence. Each is a configuration that the brain acquires to control and execute a certain skill by using the body to which it is connected. Thus, there is emotional intelligence, musical intelligence, soccer 
intelligence, and so many, many more. These configurations are absent from the brain at birth.

With the one exception of rational human intelligence, that is, the brain's OS, all these many intelligences differ from human being to human being.

So does knowledge. Knowledge, as distinct from intelligence, is less about the brain executing a skill than about the brain storing information, like knowing that Paris is the capital of France.

In terms of knowledge, no human being knows exactly the same as any other human being. Some people do not know that Paris is the capital of France. That does not make them less rationally intelligent.

But there is one kind of intelligence that needs be the same in all human beings: rational human intelligence. Rational human intelligence guarantees that one can walk up to another individual speaking the same language and expect to be understood, in spite of all the countless differences of the much other intelligence and of knowledge. One person may be good at music and another not; one person may know what the capital of, say, Croatia is and another not.

\subsection{Theory of the Brain's OS: Mathematical but Also First and Foremost Physical}

Rational human intelligence is the brain's OS. It must be universal and unchangeable. It must be shared by all people in the exact same form. That is why it has to be mathematical.

Yet, while it is mathematical, the theory of rational human intelligence is first and foremost not a theory of mathematics but rather a theory of physics. Rational human intelligence physically propagates through the human brain just as force physically propagates through the engine of a car.

\section{Framework (2): G. Boole, Pioneer}

\subsection{G. Boole and the Mathematics of the Brain's OS}

While the mathematics of physical force involves quantity, that is, the capacity of increase or diminution (and hence also rates of change in quantity, as described by calculus), the mathematics of rational human intelligence is non-quantitative. Nothing ever gets bigger or smaller.

The mathematics of the brain's OS is a digital, non-quantitative, mathematics mostly created by G. Boole. It is best known to the public at large as the mathematics that underlies a Boolean search on the Internet.

\subsection{The Reception of G. Boole's Ideas}

It is now generally assumed that G. Boole tried to, and had every intention to, describe how we think rationally but failed. The present writer has on several occasions tried to argue that the opposite is true.

G. Boole got us most of the way there. Just as I. Newton first established the fundamental laws describing how physical forces propagate in the universe, G. 
Boole first established the fundamental laws describing how rational human intelligence propagates in the human brain, the most complex structure in the universe.

J. Venn seems to be the only other person other than the present writer ever to claim with great conviction that G. Boole had achieved something that has only extremely rarely been done in the history of mankind, in this case the complete mapping of logical thought, or supplementing Aristotle's system of logic in order to make it mathematically complete.

G. Boole did acquire newfound celebrity in the age of the Internet, since his digital mathematics is the mathematics of computer chips and the Internet. But the record reveals that almost 150 years after the publication of Investigation of the Laws of Thought (1854), G. Boole's work is still mostly regarded as something of a curiosity and it has been bypassed by the history of mathematics, logic, and philosophy.

\subsection{The Difference between the Blueprint and the Cathedral}

It is proposed that the blueprint is complete while the full cathedral still needs to be built. It takes years, even decades, to build a cathedral.

How can the blueprint be at the center of all of rational human intelligence? The difference between the blueprint and the cathedral can be further clarified by a comparison.

Consider the Equation $F=m a$, force equals mass multiplied by acceleration. This Equation is part of a blueprint. Just three letters and an Equation sign. And yet, without these four symbols, it is not possible to construct an airplane that stays up in the air. The relation between the blueprint of the brain's OS and constructing G. Boole's Cathedral is of the same kind as that between $F=m a$ and building an airplane. The theory lies at the origin of everything.

\section{The Traditional Fundamental Laws of Thought}

\subsection{Definition}

The present article is not about the vast task of building Boole's Cathedral according to the complete blueprint. This effort remains on-going and will take many years, many decades, if not more. Rather, this article is for the most part about tying up loose ends. The bulk of the article is about one such loose end, the following.

The blueprint of G. Boole's cathedral presents itself as what is most fundamental about rational human intelligence. Then again, there is a competing claim that something else is fundamental. What?

For more than two thousand years before G. Boole, back to Aristotle and even before to Parmenides, it was generally accepted that it is possible to define what is most fundamental about rational human intelligence. The result was the formulation of the so-called fundamental laws of thought.

Aristotle himself seems to have thought that there was one single law of 
thought. Details follow below.

But later on, by the Middle Ages at the latest, it became common to formulate the fundamental laws of thought as being three (3) in number. They are as follows, with a simple example each to make each law immediately apparent:

1) The so-called Law of Identity, as in "A cow is a cow (and not not a cow)";

2) The so-called Law of Contradiction, as in "Something cannot be both a cow and not a cow at the same time";

3) The Law of the Excluded Middle, as in "Something is either a cow or not a cow."

The third law is well-known by the Latin expression Tertium non datur "There is no third option" (literally: "A third one is not given"). Either it is one or it is the other.

At this point, every thinking human being will probably acknowledge without hesitation that nothing could be more obvious than the three statements mentioned above. How could they not be true? Then again, why is it that everyone instantly agrees with them?

The traditional fundamental three laws of thought have completely dominated the study of philosophy and logic in the west for more than two thousand years and still do. The written record is vast.

Why is it that the three laws exemplified above have been accepted in philosophy and logic as being most characteristic of rational human intelligence? One likes to think that everything happens for a reason.

Is it possible to explain in clear physical and mathematical terms why the three laws ring so true? Such an explanation is a principal aim of the present article.

\subsection{The Traditional Laws of Thought and the Blueprint of the Brain's OS: Which Is First?}

At this point, an obvious problem arises. Clearly,

1) The physical and mathematical blueprint of G. Boole's Cathedral and,

2) the age-old traditional fundamental laws of thought in philosophy cannot both be fundamental at the same time.

To be fundamental means to rest on nothing else. Therefore, either (1) rests on (2) or (2) rests on (1). If both were the case at the same time, then both (1) and (2) would rest on something else and neither would be fundamental.

It will come as no surprise that the afore-mentioned blueprint is here considered to be the true foundation of rational human intelligence. In a strictly scientific context, physics and mathematics must trump philosophy and logic.

By the way, "logic" is a Greek word. It is first attested in the meaning that it still has today in the Roman Latin author Cicero (106 BCE - 43 BCE), who cites it in Greek. Cicero uses the feminine singular form logike (Fin. 1, 7, 22) and the neuter plural form (ta) logika (Tusc. 4, 14, 33). He calls it pars philosophiae "a part of philosophy" (Fin. 1, 7, 22). 
The aim of the present article is to establish how exactly the three fundamental laws of philosophy and logic relate to the physical and mathematical theory of rational human intelligence, the brain's OS. The aim of what follows is to show that it is possible to assign an exact place to those three laws in that theory.

\subsection{Three Questions Relating to the Fundamental Laws of Thought}

If physics and mathematics do indeed trump philosophy and logic when it comes to exact science, as I think that it should, preliminary questions readily arise with regard to the traditional fundamental laws of thought of philosophy and logic. Three preliminary questions are as follows.

Question 1:

How come that the three fundamental laws of philosophy and logic were, and still are, so widely and so readily perceived as stating something that is so fundamental about how we think? Why can the laws be called fundamental?

Question 2:

If physics and mathematics trump philosophy and logic, then are the traditional three fundamental laws of philosophy and logic wrong?

Question 3:

How do the three fundamental laws of philosophy and logic, Identity, Contradiction, and Excluded Middle, relate to one another? If they are all three fundamental, is any one more fundamental than any other? And why are there three, and not two, or not four, or any other number for that matter?

\subsection{Provisional Answers to the Three Questions Posed in 5.3}

For clarity's sake, it will be useful to begin with brief provisional answers to the three questions stated above. A complete treatment of the questions is found later in this article.

Answer to Question 1:

The three laws all three evoke the same single facet of what is fundamental about rational human intelligence. That is why they are universally perceived, not only as being true, but also as conveying the same thing. However, they far from comprehensively define what rational human intelligence is.

Answer to Question 2:

The three fundamental laws of philosophy and logic are not wrong at all. They are rather incomplete. They do not comprehensively define rational human intelligence. This comprehensive definition needs to be physical and mathematical. The true nature of the three laws can only be revealed by defining their exact place in, or in relation to, the complete physical and mathematical theory of rational human intelligence.

Answer to Question 3:

Once the place of the three laws in the complete physical and mathematical theory of rational human intelligence has been determined, each law can be converted into the two others by strictly physical and mathematical principles. 
In that sense, none of the three laws is more fundamental than the other. They are just three variations or permutations of the same general notion.

\subsection{Where Can the Traditional Laws Be Located in the Mathematics of the Brain's OS?}

The task at hand is as follows: To pinpoint the place of the traditional three laws within the realm of rational human intelligence in strictly physical and mathematical terms. It is the only way of fully elucidating what the three laws really are. In other words, the need is for establishing the exact relation between the traditional fundamental laws of thought, on the one hand, and the physical and mathematical blueprint of G. Boole's Cathedral, on the other hand.

The aim is to pinpoint the exact location of the laws in the blueprint. Towards that purpose, it will be necessary to survey the complete geography of the blueprint in order to be able to pinpoint the location of the laws in that blueprint.

The fundamental laws of thought have generally been considered to be the domain of philosophy and logic. The present article is about making them part of physics and mathematics.

\section{A Past Effort to Relate the Traditional Laws to Mathematics: A. N. Kolmogorov}

\subsection{Law of the Excluded Middle}

The question arises: Have there been any efforts to incorporate the fundamental laws of thought into mathematics or exact science instead of just leaving the study of them to philosophers and logicians?

I have not undertaken anything close to a detailed search for such efforts. But the most prominent such effort may well be the 1925 doctoral dissertation by the celebrated Russian mathematician A. N. Kolmogorov. The original is evidently in Russian. But an English translation has been published [2]. A. N. Kolmogorov's dissertation is concerned with the law pertaining to the Excluded Middle, the third of the three laws according to the random order presented above.

Since the present article is about incorporating the traditional laws of thought into mathematics and science, it will be useful to establish right at the outset how A. N. Kolmogorov's effort compares to the present effort.

\subsection{Principal Difference between the Present Approach and A. N. Kolmogorov's}

There is a fundamental difference between A. N. Kolmogorov's approach and the present approach. A. N. Kolmogorov's dissertation is an effort to incorporate the fundamental laws of thought, or at least the law of the Excluded Middle, into mathematics. But importantly, only mathematics. Apparently, A. N. Kolmogorov's desire is to convert the laws into a purely mathematical theory.

By sharp contrast, the present article's effort is to incorporate the fundamental laws of thought into a theory of physics, not a pure theory of mathematics as A. N. Kolmogorov would have it. 
But like any theory of physics, the present theory does come with mathematics. However, the mathematics is not the familiar quantitative mathematics, but rather the non-quantitative mathematics mostly formulated by G. Boole, a mathematics that is often called Boolean algebra, rightly so.

A. N. Kolmogorov's approach therefore differs so radically from the approach taken here that it will play no role whatsoever in what follows. The task of comparing A. N. Kolmogorov's approach with that of the present article will need to be left to others. One thing seems certain. The gap between the two approaches seems huge, if not insurmountable. I do not see how they can both be right at the same time. But again, let others judge about the matter.

In the end, A. N. Kolmogorov's approach is to construct a mathematical theory. But rational human intelligence is a physical event that happens in the physical medium of the brain. The theory of the OS of the brain must therefore first and foremost be a theory of physics and only secondarily a theory of mathematics. What is more, in as far as the theory is mathematical, the mathematics is not the usual quantitative mathematics that everyone is used to. It is a mathematics in which nothing ever gets bigger or smaller. It is a digital mathematics.

Another effort similar to A. N. Kolmogorov's by L. E. J. Brouwer will not be discussed in detail here [3].

\section{Relation between the Physical and Mathematical Theory of the Brain's OS and the Traditional Laws of Thought: The Key Question}

The physical and mathematical theory of rational human intelligence as proposed elsewhere by the present writer is deemed complete, even if details still need to be fleshed out.

By contrast, the traditional fundamental laws of thought do not constitute a complete theory or system.

The need is for relating the traditional laws of thought to the blueprint of the complete theory of rational human intelligence. Both are deemed to be valid. But the theory is assumed to be complete whereas the laws are not. It follows that the laws refer to part of the complete theory, and not the other way around.

It also follows that the traditional laws in some sense do not deserve the designation "fundamental."

Then again, it will be argued below that the traditional laws of thought do point to a fundamental property of rational human intelligence.

If the traditional laws of thought do indeed refer to a fundamental property of rational human intelligence, then it should be possible to locate the laws somewhere close in relation to the very foundation of the brain's OS. How so?

\section{The Physics and Mathematics of the Brain's OS: Overview}

\subsection{Digitalities, Levels, Operators}

I have elsewhere described the physical and mathematical theory of rational 
human intelligence [1]. This is not the place to detail the complete blueprint all over again. Suffice it to present the following comprehensive list of its main components.

The brain's OS consists of exactly six (6) digitalities, three (3) levels, and nine (9) operators. One new digitality and one new operator are introduced in the present article (see below).

On the physical side, there are six (6) digitalities or six flavors of digitality. Existence Digitality is newly proposed in the present article. The six flavors are as follows.

1) Contrast digitality

2) Selection digitality

3) Nexus digitality

4) Existence Digitality

5) Supplement digitality

6) Certification digitality

Also on the physical side, these six (6) digitalities play out on three (3) levels:

1) The primary level

2) The secondary level

3) The tertiary level

G. Boole describes the first two levels, primary and secondary. I have deemed it necessary to add a tertiary level to make the theory of the brain's OS complete.

On the mathematical side, digital non-quantitative mathematics has its operations just like quantitative mathematics. The operations of quantitative mathematics are addition, subtraction, multiplication, powers, roots, and so on.

The nine (9) operators of digital mathematics are as follows:

1. NOT

2) NOT NOT

3) AND

4) OR

5) IS

6) THERE IS

7) 1 (the "universe," or all that one could possibly think of)

8) 0 (nothing)

9) / (“division")

The operator THERE IS is newly introduced in the present article.

\subsection{The Single Principle from Which the Brain's Entire OS Is Derived}

The traditional laws of thought do not comprehensively refer to all of rational human intelligence.

Then again, the insistence and emotion and energy with which the laws of thought are repeated over and over again and documented by countless expressions in daily speech over many centuries (for evidence, see below) suggests efforts to refer to something that is truly essential about rational human intelli- 
gence.

The question arises: What is most essential about rational human intelligence?

The present writer has proposed elsewhere that all of rational human intelligence can be derived from one single principle, only one-in the same way that J.-L. Lagrange derived all of the physics of matter and motion from a single principle.

That single principle is the contrast between what something is and what it is not. It involves the operator NOT.

It will be proposed below that it is exactly this principle that the brain attempts to evoke in a non-physical and non-mathematical way.

The traditional laws of thought express a deep desire to state what is most essential about how we think logically.

\section{The Mathematical Interpretation of the Traditional Laws of Thought}

\subsection{Locating in the Laws the Single Principle from Which the Brain's Entire OS Is Derived}

It will be useful to recall the formulation of the three laws:

1) "A cow is a cow (implied: and not not a cow)." (Law of Identity)

2) "Something cannot be both a cow and not a cow at the same time." (Law of Contradiction)

3) "Something is either a cow or not a cow." (Law of the Excluded Middle)

All three laws clearly involve the contrast between what something is and what it is not. In the examples above, the contrast in each of the three laws is between what is a cow and what is not a cow.

In a Boolean and digital context, as J. Venn emphasized even better than Boole himself, all that is a cow and all that is not a cow are both classes of entities.

Evidently, the three laws do not state explicitly in a physically and mathematically reflective way that the contrast between what something is and what it is not is the fundamental principle of rational human intelligence. That would be a little too technical for common speech.

Instead, the three laws of thought evoke the fundamental physical and mathematical principle of rational human intelligence in a more indirect way. And this gets us to the next question. How do they do so?

\subsection{Means by Which the Laws Refer to the Single Principle: The Operator IS}

The three laws of thought are statements or full sentences. That means that, in terms of the physical and mathematical theory of human intelligence, all three involve the nexus operator IS.

To speak in full sentences is the standard mode of communication between human beings. Human beings typically do not endeavor to ask theoretical ques- 
tions like the ones asked in the present article. Instead, they try to make statements in full sentences that seem to make basic sense to them in order to express intuitively what is deeply felt.

In the physics and mathematics of rational human intelligence, the operator IS is the link or nexus between two classes or entities or attributes.

In the traditional laws of thought, there are two entities: (1) what is X (e.g., a cow) and (2) what is not X (e.g., not not a cow), as follows.

1) "A cow IS a cow (and not not a cow)." (Law of Identity)

2) "Something cannot BE both a cow and not a cow at the same time." (Law of Contradiction)

3) "Something IS either a cow or (IS) not a cow." (Law of the Excluded Middle)

The three laws of thought represent three ways in which the contrast between what something is and what it is not, the fundamental principle that lies at the origin of all rational human intelligence, that is, of the brain's OS, is expressed by the operator IS.

\subsection{All the Theoretical Ways in Which IS (=) Can Be Mathematically Related to the Contrast between What Something Is and What It Is Not}

The three traditional laws of thought are apparently three ways of giving expression to the same fundamental principle from which the brain's entire OS is derived by means of the operator IS.

The need is for evaluating and rephrasing the traditional laws of thought in physical and mathematical terms. Where are they located in relation to the physical and mathematical theory of rational human intelligence?

In order to locate the traditional laws more precisely, it will be necessary to map all the possible physical and mathematical ways, at least theoretically, in which the relation between what something is and what it is not can be related to the operator IS.

The relation is between the following three elements.

1) The operator IS, represented in Boole's algebra by the symbol =;

2) what something is, represented in Boole's algebra by $x$,

3) what something is not, represented in Boole's algebra by $1-x$, that is, the universe (1) or everything one could possibly think about, minus $x$, G. Boole tends to abbreviate it to $\bar{x}$.

But first, it needs to be noted that the relation can be expressed on two levels of thought.

\subsection{The Two (2) Levels of Thought on Which IS (=) Can Be Mathematically Related to the Contrast between What Something Is and What It Is Not}

G. Boole was the first to describe the two levels of thought. I have noted elsewhere that there is an additional third level of thought and I have described it at 
length. But this third level does not play a role in the present context.

According to G. Boole, the first level concerns the relation between things and the second level concerns the relation between statements about things.

The relation between $=, x$, and $1-x$ can be expressed on both levels of thought. On the first level of thought, there is just one (1) instance of the operator IS. On the second level of thought, two statements each with its own operator IS are related to one another by means of a third operator IS. That means that, on the second level of thought, there are in fact three (3) instances of the operator IS, one for each of two statements and one that connects the two statements.

\subsection{The Three (3) Ways in Which IS (=) Can Be Mathematically Related to the Contrast between What Something Is and What It Is Not on the First Level of Thought}

On the first level of thought, there is just one Equation and therefore one instance of IS (=), as follows:

$$
?=\text { ?. }
$$

Therefore, if one wishes to enter both $x$ and $1-x$ into this Equation, there are strictly theoretically only two (2) ways of doing so.

The first way is to enter the two on either side of the Equation, as follows:

$$
x=1-x .
$$

The second way is to enter both on the same side, as follows:

$$
x \ldots 1-x=\text { ?. }
$$

This second way contains the expression

$$
x \ldots 1-x .
$$

This expression is positioned to one side of the operator IS. It is therefore a class or an attribute. But it is also a class or attribute composed of two other classes or attributes.

There are only two (2) mathematical means of combining two classes or attributes into a single class or attribute by means of Boolean algebra as the mathematics of rational human intelligence. They are the operators AND and OR.

Accordingly, the Equation

$$
x \ldots 1-x=\text { ? }
$$

can be reformulated in two (2) and only two ways, as follows:

1) $x$ AND $1-x=$ ?, or also $x(1-x)=$ ?, or also $x \bar{x}=$ ?;

2) $x$ OR $1-x=$ ?, or also $x+(1-x)=$ ?, or also $x+\bar{x}=$ ?.

It may be concluded that there are exactly three (3) purely mathematical ways of relating the contrast between what something is and what it is not to the operator IS on the first level of thought:
1) $x=\bar{x}$;
2) $x \bar{x}=?$;
3) $x+\bar{x}=$ ? 
These are the purely mathematical parameters in relating $=, x$, and $1-x$ to one another. Evidently, the physical perspective still needs to be considered. From the perspective of physics, the two questions at hand are: 1) Which purely mathematical possibilities are physically realized in the medium of rational human intelligence? 2) And how?

\subsection{The Three (3) Ways in Which IS (=) Can Be Mathematically Related to the Contrast between What Something Is and What It Is Not on the Second Level of Thought}

Again, on the first level of thought, there are only three (3) ways of purely mathematically relating $=, x$, and $1-x(\bar{x})$ to one another. They are the following:

1) $x=\bar{x}$

2) $x \bar{x}=?$;

3) $x+\bar{x}=$ ?.

These three ways were obtained by determining how, purely mathematically, two classes $x$ and $1-x$ can be added to the Equation

$$
\text { ? = ?. }
$$

On the second level of thought, two (2) Equations corresponding to two (2) statements on the first level of thought are equated with one another. There are therefore three (3) Equations in total, two (2) on the first level and one (1) on the second level.

This state of affairs can be represented as follows.

$$
[?=?]=[?=?] \text {. }
$$

The task at hand is again to determine in how many purely mathematical ways the classes $x$ and $1-x$ can be entered into these three Equations.

The first observation is that the two classes $x$ and $1-x$ need to be distributed across the two Equations or statements on the first level of thought. Otherwise, one of the two Equations would be without any reference to a class. The result is the following two Equations on the first level of thought:

$$
\begin{gathered}
?=x ; \\
?=1-x .
\end{gathered}
$$

The next step is to relate these two statements on the first level of thought to the Equation on the second level of thought.

As with placing the two classes of things $x$ and $1-x$ in relation to $=$ on the first level of thought, there are two ways of placing the two classes of statements $?=x$ and $?=1-x$ in relation to $=$ on the second level of thought.

The first way is to enter the two classes on either side of $=$, as follows:

$$
[?=x]=[?=1-x] \text {. }
$$

The second way is to enter both classes on the same side of $=$, as follows:

$$
[?=x \ldots ?=1-x]=? .
$$

In the second way, the expression $[?=x \ldots ?=1-x]$ is positioned to one 
side of the operator IS. It is therefore a class, not a class of entities as on the first level of thought but a class of statements or events in the broadest sense of the word. But it is at the same time a class composed of two other classes of events. It is therefore a class of compound events.

There are only two (2) mathematical means of combining two classes into a single class by means of Boolean algebra as the mathematics of rational human intelligence. They are the two operators AND and OR.

Accordingly, the class of events denoted as

$$
[?=x \ldots ?=1-x]
$$

can be reformulated in two (2) and only two ways, as follows:

1) $[?=x$ AND $?=1-x]$;

2) $[?=x$ OR $?=1-x]$.

It may be concluded that there are exactly three (3) purely mathematical ways of relating the contrast between what something is and what it is not to the operator IS on the second level of thought, just as there are three (3) on the first level of thought, as follows:

1) $?=x$ IS $?=1-x$;

2) $[?=x$ AND $?=1-x]$ IS ?;

3) $[?=x$ OR $?=1-x]$ IS ?

These expressions can be simplified in terms of notation if

$$
?=x
$$

is represented as

$$
X
$$

and

$$
?=1-x
$$

as

$$
\bar{X} \text {. }
$$

Accordingly, the three Equations above can be represented as follows:

1) $X=\bar{X}$

2) $X \bar{X}=?$;

3) $X+\bar{X}=$ ?

\section{Resolving the Question Marks in the Six (6) Equations Combining IS, NOT, AND, and OR in Relation to One Entity}

\subsection{The Six (6) Equations}

Six (6) Equations have been obtained above through purely mathematical means. They constitute all the purely mathematical possibilities in which the contrast between what something is and what it is not can be related to the operator IS.

These six Equations are as follows: 
I: $x=\bar{x}$

II: $x \bar{x}=?$;

III: $x+\bar{x}=$ ?;

IV: $X=\bar{X}$

$\mathrm{V}: \quad X \bar{X}=? ;$

VI: $X+\bar{X}=$ ?.

The six Equations together define in precise mathematical terms the limitations beyond which it is not possible to think about how the contrast between what something is and what it is not relates to the operator IS.

But there is more room for editing the Equations in purely mathematical terms by resolving the four (4) question marks.

In Boolean algebra, there is no doubt that the four question marks need to be resolved as follows:

II: $x \bar{x}=0$;

III: $x+\bar{x}=1$

$\mathrm{V}: \quad X \bar{X}=0$;

VI: $X+\bar{X}=1$.

The six Equations together consist in their entirety of the six mathematical and Boolean operators NOT, IS, AND, OR, 1, and 0.

The six (6) Equations constitute all the purely mathematical perimeters for studying the most fundamental property of how we think rationally. Now, it is necessary to make sense of these perimeters in terms of the physics of rational human intelligence. It should then be possible to establish how the three (3) traditional laws of thought relate to the more fundamental physical and mathematical theory of rational human intelligence.

The three (3) laws of nature are linguistic expressions. In order to establish as precisely as possible the relation between the laws and the six (6) Equations, it will be useful to give linguistic expression to the six (6) Equations as well and then evaluate the resulting expressions.

\subsection{Equation I: $x=\bar{x}$}

Equation I can be rendered linguistically as, for example, "A cow is not a cow" or as "Cows are not cows," perhaps less likely as "The cow is not the cow."

There is a problem with these expressions. They do not make sense. In fact, they state exactly the opposite of what is the truth because nothing of what is $x$ is not- $x$ and nothing of what is not- $x$ is $x$.

Is it then at all possible to relate $x$ and $1-x$ in some way by placing them at both sides of IS as is desired? It is. Before defining how so, it will be necessary to have a closer look at the Equation

$$
x=x .
$$

\subsection{The Equation $x=x$}

In Boolean algebra, this Equation can also be expressed as follows: 


$$
x=x x \text {. }
$$

I refrain from entering into detail about the difference between the two expressions. The difference is irrelevant to the present argument. The focus is on

$$
x=x \text {. }
$$

Linguistic expressions of this Equation are "A cow is a cow" and "Cows are cows."

The problem with the Equation

$$
x=\bar{x}
$$

is that it is not true. On the other hand, the problem with the Equation

$$
x=x
$$

is that it does not seem to say anything. It is completely tautological. And yet, everyone says it all the time. It will be useful to establish the very fact of its ubiquity.

\subsection{The Ubiquity of the Equation $x=x$ in Daily Speech}

At first sight, “A cow is a cow” looks like a meaningless sentence. J. Locke called it a "trifling proposition" (see below). But why then does everybody make this kind of statement all the time as endless alterations of the Law of Identity?

It never ceases to amaze how frequent statements of the type "A cow is a cow" are. Just in case one might think that they are an aberration of colloquial daily speech, what follows are five examples of official statements involving leading personalities.

In the New York Times of February 3, 2005, at p. A5, a certain Dr. Allegra comments on an apparent improvement in the health of the then ailing Pope John Paul II: "The pope is the pope. He has been through a lot. We are used to miracles from him."

The following four statements were made within a short period in early 2008 .

In the New York Times of January 8, 2008, at p. C1, an unnamed law firm partner comments as follows about a memo by Martin Lipton, a well-known American corporate lawyer: "Marty will be Marty, but that note takes the cake."

In the New York Times of February 14, 2008, at p. A26, someone is cited as making the following statement about the current delegate counts of the two presidential candidates Hillary Clinton and Barack Obama: "The math is the math."

In the New York Times of February 24, 2008, at p. A1, Raul Castro, the president of Cuba, is cited as stating about his brother Fidel Castro, in Spanish: Fidel es Fidel "Fidel is Fidel."

In CNN Internet news of March 12, 2008, Geraldine Ferraro, who was a US vice-presidential candidate in 1984, replies to the controversy that she has stirred up by her suggestion that presidential candidate Barack Obama's 2008 campaign was successful because he is black: "I am who I am and I will continue to speak 
up".

And does anyone need to be reminded of Gertrude Stein's dictum that "A rose is a rose is a rose is a rose"? Then there is the signature song in the celebrated motion picture Casablanca.

You must remember this.

A kiss is just a kiss, a sigh is just a sigh.

The fundamental things apply.

As time goes by.

This song even adds in regarding to tautological statements: "The fundamental things apply." How surreptitiously insightful regarding the deepest foundations of rational human intelligence.

I also note the frequency of a statement like "It is what it is" (for example, B. McNamee on the phone with R. Clemens, reported on National Public Radio, February 14, 2008). It is remarkable how often people make a statement like this in all kinds of contexts.

These "trifling propositions" can also relate two statements to one another, as in "The only thing about Randy is, when he's right, he's right" (Boston Globe, January 20, 2008, p. C7).

A selection of other examples: "I don't have time to argue. I need you here. That's that. That's that" (Film 3:10 to Yuma, dir. J. Mangold, 2007); Schuld is schuld "Guilt is guilt" (Dutch film Character, 1997, dir. M. Van Diem); "When I was young and irresponsible, I was young and irresponsible" (G. W. Bush, frequent campaign trail statement reported in the Boston Globe, 16 December 2007, p. D9); Une femme est une femme "A woman is a woman" (title of French 1961 film, dir. J.-L. Godard; (woman) "Send postcards from exotic ports of call. That's what you call'em, isn't it? ..." (answer K. Costner character) "A port's a port. You're exotic" (film No way out, 1987, dir. R. Donaldson); "He cannot be but what he is" (TV series Rome, dir. M. Apted, episode 2, 2005); "Business is business" (film Last Man Standing, 1996, dir. W. Hill); (of supply of 500) "When they're gone, they're gone" (radio commercial WCRB Boston, 26 August 2006); "Hey, you're right. What's right is right" (film House of Games, 1987, dir. D. Mamet); "If you stay home, you stay home" and "Your life is your life" (book The Memory Keeper's Daughter, 2005, by K. Edwards, pp. 277 and 397); "When you're right, you're right. And you're right" (film Chinatown, 1987); "The deadline is the deadline" (New York Times, 5 February 2005, p. B2); "If you're alive, you're alive. That's life (New York Times, 29 December 2004, p. A10, on aftermath of tsunami); "When it's broken, it's broken" (film L'auberge espagnole, 2003, dir. C. Klapisch); "When you're right, you're right" (film GoodFellas, 1990, dir. M. Scorcese). And so on.

The question arises: Why do people make these statements all the time if, at first sight, they are seemingly devoid of meaning? There must be a deeper reason.

There appears to be a universal perception that the Equation 


$$
x=x
$$

says something truly fundamental about the way in which we think rationally. However, the most fundamental principle from which all of rational human intelligence is derived is the contrast between what something is, say $x$, and what something is not, $1-x$.

On the one hand, the Equation

$$
x=1-x
$$

satisfies the requirement of relating $x$ and $1-x$ by means of the operator IS. But it makes no sense. It completely contradicts the physics of rational human intelligence.

On the other hand, it cannot be said that the Equation

$$
x=x
$$

is wrong. But there seems to be little point in stating it.

The present aim is still to somehow try to connect $x$ and $1-x$ by means of the operator IS. How to proceed from here? Is there a way of doing so? And, if so, what should be the point of departure of the following argument?

I believe that there is a way of doing so. And I also believe that the Equation

$$
x=x
$$

needs to be the point of departure because it is so ubiquitous. Why does this expression so often seem to make sense to so many?

The first step is to introduce a new class into the argument. So far, the argument has been concerned with the following two classes: 1) $x$ and 2) 1-x. The latter class refers to the universe (1), or all one could possibly think about, minus $x$.

But there is a third class that deserves consideration. It can be represented as 1 $-(1-x)$.

\subsection{The Classes $x, 1-x$, and $1-(1-x)$}

The class $x$ represents all that is $x$. Therefore, the class $1-x$ is all that one could possibly think about (what G. Boole calls the universe and represents by 1 in his algebra) minus $x$. The expression $1-x$ involves the mathematical operator NOT.

The class $1-x$ can be called the negation of the class $x$. The negation is effected by the operator NOT.

Because $1-x$ is a class, it too can be negated. The result may be represented as $1-(1-x)$. But it is obvious that, in Boolean algebra, this expression can be rephrased as $1-1+x$. And therefore also as just $x$. Therefore, NOT NOT $x$ equals just $x$.

It is proposed here that the class $1-(1-x)$ can be applied to expand the Equation

$$
x=x
$$


so as to relate the class $x$ with the class $1-x$. How so?

The use of double negations is quite common in most if not all languages, for example, in "He is not unfriendly." Even triple negations are possible, as in "I am not saying that he is not unfriendly."

But the present concern is with a non-lexical type of double negation, namely the one implied in the expression of contrastive emphasis, as in "He arrived Saturday" or "It is on Saturday that he arrived."

Much has been written about contrastive emphasis. I have elsewhere proposed and discussed at length that all contrastive emphasis needs to be defined digitally. In that sense, "He arrived Saturday" or "It is on Saturday that he arrived" implies "Saturday, NOT NOT Saturday." This expression can be rendered in Boolean algebra as follows:

$s(1-[1-s])$.

Which is evidently the same as

$s(1-1+s)$;

and the same as

$s(0+s)$;

and as

SS;

or also as just

$S$.

How is this relevant to the analysis of the law "A cow is a cow"?

\subsection{The Equation $x=x$ "A Cow Is a Cow" and the Class $1-x$}

Why are at first sight meaningless statements such as "A cow is a cow" so frequent?

One has every impression that they are typically a reaction against the notion that a cow could not be a cow. It is therefore deemed necessary to confirm that a cow is indeed a cow and nothing else, that is, NOT NOT a cow.

In fact, a statement such as "A cow is a cow" is often pronounced as "A cow is a cow," it seems to me. Further observation remains desirable. But the specific higher or stronger pitch affecting the second instance of "a cow" clearly implies that the statement "A cow is a cow" means that a cow is a cow and not something else, that is, not not a cow." The mathematical representation of this statement in Boolean algebra is evidently as follows, with $c$ standing for "a cow": $c=c(1-[1-c])$.

Upon resolution of the negations, this Equation is evidently the same as: $c=c c$.

Stating that "A cow is a cow" conveys the same information as stating that "A cow is a cow." But there is a digital moment in the latter statement. There is a reference to that which is not a cow.

In fact, the effect of contrastive emphasis is to conjure up a second nexus. In that sense 
$c=c(1-[1-c])$ "A cow is a cow"

at the same time implies

(nexus no. 1) $c=c$ "A cow is a cow"

and

(nexus no. 2) $c=1-(1-c)$ "A cow is not not a cow (or not a non-cow)"

It is obvious that, of the three traditional laws of thought, the so-called Laws of Contradiction and the Excluded Third Middle make reference to the contrast between what something is and what it is not. But the matter is not immediately obvious in the case of the so-called Law of Identity, exemplified by "A cow is a cow."

Upon closer inspection, however, it seems now clear that the Law of Identity refers just as much as the other two laws do to the contrast between what something is and what it is not. There is this deep sense that the contrast between what something is and what it is not has everything to do with how we think rationally.

\subsection{Equation II ( $x \bar{x}=0)$ and Equation III $(x+\bar{x}=1)$}

A possible close linguistic equivalent of Equation II is "Nothing (Boole's 0) is both $x$ and not $x$ " or, in concrete terms, "Nothing is both a cow and not a cow."

A possible close linguistic equivalent of Equation III is " $x$ and not $x$ together are everything thinkable (Boole's 1)," or phrased in more concrete terms, "Everything (1) consists of cows and non-cows."

\subsection{Equation IV ( $X=\bar{X})$, Equation V $(X \bar{X}=0)$, and Equation VI $(X+\bar{X}=0)$}

As G. Boole noted, rational human intelligence operates on two levels, 1) statements about relations between things, as in "The sun is shining" (describing a relation between the sun as a thing and things that are shining), and 2) statements about events, as in "When the sun shines, the earth warms up" (describing a relation between the event of the sun shining and the event of the earth warming up).

Accordingly, $X$ and $\bar{X}$ are statements in the three Equations IV, V, and VI mentioned above and the three Equations express relations between the two statements $X$ and $\bar{X}$ by means of the operator IS (=). The Equations IV, $\mathrm{V}$, and VI are therefore Equations of two Equations, or Equations to the second degree as it were.

Each of the three Equations IV, V, and VI therefore mathematically involves three (3) instances of the operator IS (=): the two statements $X$ and $\bar{X}$ both include the operator IS (=) and, in addition, the two statements are linked by means of the operator IS (=).

What is more, the two Equations that are equated with one another in a third overarching Equation need to contain both what is $x$ and what is not $x$. But $x$ and not- $X$ cannot be assigned to the same Equation. That would leave nothing to 
be expressed in the other Equation. They therefore need to be distributed across the two Equations.

All these mathematical considerations inevitably lead to the following schematic representation of the Equations IV, V, and VI.

Equation IV $(X=\bar{X})$ :

$$
[?=x]=[?=1-x]
$$

Equation $\mathrm{V}(X \bar{X}=0)$ :

$$
[?=x] \text { AND }[?=1-x]=0 .
$$

Equation VI $(X+\bar{X}=1)$ :

$$
[?=x] \text { OR }[?=1-x]=1 .
$$

These three Equations define the absolute mathematical limits of how one can relate what something is and what it is not by means of the Equation IS (=) on the second level of thought, the level of the events. As G. Boole was the first to show, the mathematical structure of the second level is exactly the same as that of the first level.

The need is for converting these mathematical constraints into how people speak naturally.

The problem is the question mark. What does it stand for? It will be useful to represent the symbol "?" by neutral "it," for lack of a better term. An alternative is "something."

A first attempt to turn the above Equations into natural human speech is as follows.

Equation IV:

$[$ It $/$ Something $=x]=[$ It $/$ Something $=1-x]$.

"That something is $x$ means the same as that it is not $x . "$

Equation V:

$[$ It $/$ Something $=x]$ AND $[$ It $/$ Something $]=1-x]=0$.

"That something is $x$ and that it is at the same time not $x$ does not occur."

Equation VI

$[\mathrm{It} /$ Something $=x]$ OR $[\mathrm{It} /$ Something $=1-x]=1$.

"That something is $x$ or that it is not $x$ constitute all possible cases."

Like the first of the three Equations on the first level of thought, the first of the three Equations on the second level of thought is contradictory. In order to assert what is fundamental about the laws of thought, it therefore needs to be contradicted in the following manner.

"That something is $x$ means that it is $x$ (and nothing else)."

This is the equivalent, on the second level of thought, of the expression " $\mathrm{A}$ cow is a cow" on the first level of thought.

There are again two nexuses, the following:

1) "That something is $x$ means that it is $x$ ";

2) "And it does not mean that it is not $X$ (or: And it is not non- $x$ )." 


\subsection{Why Three Traditional Laws of Thought and Not, Say, Two or Four?}

For so many centuries now, there have traditionally been three so-called fundamental laws of thought. These three fundamental laws have been phrased in countless different idioms across many languages. This is not the place for a linguistic study of all this diversity. It will suffice for the present purpose to note that all idioms can be securely assigned to one of the three traditional laws. But this task will need to be left to another occasion.

But why three? Why not two, why not four, and so on? Is there a justification for the number three? And what is that justification? The laws of thought have been discussed so often for more than two thousand years. But nowhere does one find an explicit justification for the number three.

There are three possibilities: 1) the number three can be positively justified in scientific terms; 2) the number three can be positively falsified in scientific terms; 3 ) the matter is not clear.

The conclusion that follows from all that has been said above is that possibility 1) definitely applies: the number three is supported by strictly mathematical arguments, even though the laws of thought have never been considered as part of mathematics but rather of philosophy and logic.

Apparently, some kind of intuition and long reflection about what is most fundamental over many, many centuries led to an insight that more or less overlaps with the strictly mathematical truth about how many ways there are in which one can formulate the relation between what something is and what it is not. And the number of ways is three (3), no more, no less.

Then again, the three (3) ways can be expressed on two different levels, the level of the things and the level of the sentences. There are therefore two (2) modalities for each of the three (3) ways, for a total of six (6) modalities.

Some of the many linguistic expressions of the three laws of thought can be associated with the level of the things and others can be associated with the level of the sentences.

For example, the law of contradiction could be expressed on the first level as "Nothing is both a cow and not a cow" and on the second level as "That something is a cow and that it is at the same time not a cow is impossible."

There is no record, in more than two millennia of discussion about the fundamental laws of thought, as far as I know, of the existence of the two levels. The credit for distinguishing the two levels, and above all the fact that both exhibit the exact same mathematical structure in the human brain's OS, is entirely owed to G. Boole. But no one is really aware of it these days. The reason may well be the generally held opinion about G. Boole's work that he tried to explain how we think rationally and failed.

I have elsewhere proposed that there is actually a third level, beyond G. Boole's two levels. But the third level is not immediately relevant to the present discussion. It will not be further discussed here. But it remains deeply relevant to an understanding of the constitution of the brain's OS. 


\section{The Foundations of the Brain's OS: Physical Laws or Mathematical Axioms?}

\subsection{Answer: Both}

It is reasonable to assume that there must be something fundamental about rational human intelligence, that is, the brain's OS. The search is for what most fundamentally characterizes the brain as it thinks rationally.

In physics, what is most fundamental is typically described as laws. In pure mathematics, what is most fundamental is typically described as axioms.

I have elsewhere proposed a complete blueprint of rational human intelligence, the brain's OS. According to this blueprint, the theory of the brain's OS is a theory of physics with its own, digital, mathematics designed by G. Boole.

What matters most at this juncture is to conclude that, if the theory of the brain's OS is both physical and mathematical, then it ought to exhibit both laws and axioms. What is more, the theory is first and foremost a theory of physics. Therefore, the laws take precedence.

Examples of the physical laws of the brain's OS and the mathematical axioms of the brain's OS will be presented below.

\subsection{Laws or Axioms? G. Boole's Point of View}

It will be useful to anticipate the conclusion right away. G. Boole thought that he was doing mathematics. I doubt that he realized that he was working on a theory that is in the first place a theory of physics as we would define it today. In any event, it is somewhat contradictory that the title of his seminal 1854 book, $A n$ Investigation of the Laws of Thought, contains the word "laws," which is more commonly used for the laws of nature, that is, physical laws, whereas what he thought that he was doing was mathematics.

Then again, much of his An Investigation of the Laws of Thought was devoted to creating the non-quantitative mathematics that is needed to describe rational human intelligence properly. Much was already accomplished in his earlier Mathematical Analysis of Logic (1847), which does in fact have the word "mathematical" in the title. The fact that much of G. Boole's efforts were indeed mathematical may have detracted attention away from the other fact that, deep down, the theory of the brain's OS must be a theory of physics.

It needs to be granted that, in G. Boole's day, the distinction between physics and mathematics was not as sharp as it is today. I therefore believe that G. Boole did not distinguish as sharply as one could between the two things that he was doing at the same time: first, something very much akin to I. Newton's laws; and second, something very much akin to Euclid's axioms.

For much of early modern times, someone active in pure mathematics and even physics was called a geometer. L. Euler was known as a geometer. J.-L. Lagrange was known as a geometer. Both were active in both physics and mathematics by the current definitions of the terms. Then again, their physics was theoretical and not experimental. It is when experimenting in labs became a full 
time job, especially in the wake of the work by M. Faraday and others, that a physicist came to be typically thought of as running experiments in a lab with all kinds of outfits whereas a mathematician spends time in a classroom writing on a blackboard.

G. Boole had very little appreciation for the fact that he was doing two completely different things at the same time. By all appearance, he appears to think that he is doing just one thing, for the most part what is presently classified as mathematics.

All this is in danger of leaving anyone reading G. Boole from a modern perspective confused. I believe that this confusion has contributed to the prevailing opinion that G. Boole tried to describe how we think rationally and yet failed.

G. Boole's theory of the brain's OS has been for the most part interpreted by himself and everyone else as a theory of mathematics. It is only partly, and secondarily, a theory of mathematics. It is first and foremost a theory of physics.

The mathematical component derives its prominence from at least two facts. The first fact is that the mathematics created by G. Boole to serve as a vehicle of the physical theory of the brain's OS was so completely new and different. The second fact is that Boolean algebra became the mathematics that runs computers. And in this internet age, computers never cease to fascinate. These two facts are not likely to encourage the view held by the present writer that the theory of the brain's OS needs to be first and foremost a physical theory.

Earlier, G.W. Leibniz and J. Lambert had tried to create an algebra with similarities to G. Boole's, with some measure of success, more in the case of J. Lambert than in the case of G. W. Leibniz, though G. W. Leibniz is more prominent in common memory than J. H. Lambert. But their systems are not comprehensive mathematical systems. They fall far short. And they are not nearly sufficient to build an artificial intelligence that replicates the human brain. G. Boole's system does.

G. Boole was a great admirer of I. Newton. It is remarkable that, when he created his theory of the brain's OS, he was not fully aware of creating a theory of physics, just as his idol I. Newton had.

To clarify the present writer's position once again: according to the proposed blueprint, the theory of the brain's OS is a theory of physics with its own, digital, mathematics. The task at hand is therefore to identify what is law in G. Boole's theories and what is axiom in G. Boole's theories even if G. Boole himself did not make the distinction.

In order to reach an adequate understanding of the brain's OS, and some day build something like it by artificial means, it is crucial to realize, 1), that its theory is both a theory of physics and a theory of mathematics, and 2), that the mathematics in question is not the usual quantitative mathematics but rather a digital mathematics designed by G. Boole.

I provide some more evidence about G. Boole's approach. I believe that there are clear indications of the following two tenets. 
Tenet 1: G. Boole conflated physics and mathematics.

Tenet 2: G. Boole himself thought that he was doing something akin to what is now called mathematics rather than to what is now called physics.

Evidence for Tenet 1: G. Boole did give his seminal work of 1854 the title $A n$ Investigation of the Laws of Thought. The term "laws" reminds one of I. Newton's laws. They are laws of physics. However, at some point in his Laws (p. 35), he makes reference to the "laws, or as usually be said, the axioms." Axioms are part of mathematics. Clearly, G. Boole explicitly equates the two.

In fact, G. Boole even includes Aristotle and Greek philosophy into the picture. Therefore, he seems to conflate not only physics with mathematics, but also both physics and mathematics with philosophy.

Philosophy can safely be excluded from the picture. According to the proposed blueprint, the theory of the brain's OS is a theory of physics with its own, digital, mathematics. It is not a philosophical theory. It is a scientific theory.

Evidence for Tenet 2: G. Boole otherwise leaves no doubt that he is doing mathematics when he states that "the ultimate laws of Logic are mathematical in their form" (Laws, p. 11).

Outside of his work on "logic," G. Boole's work would in modern terms be described as mathematics, differential Equations and such. In no way was G. Boole someone conducting experiments in laboratories.

G. Boole was a great admirer of I. Newton. Both were from Lincolnshire in England. The young G. Boole lectured about I. Newton in the city of Lincoln in his late teens, showing a complete understanding of I. Newton's theories and even critiquing those theories. And yet, he never seemed to think that he was describing a theory of physics just as his idol I. Newton was. How interesting. Or was he somehow without making it explicit?

\subsection{Eminent Known Examples of Physical Laws and Mathematical Axioms}

Before defining what the physical laws and the mathematical axioms of rational human intelligence are, it may be useful to look at some famous examples of both laws and axioms first.

When it comes to physical laws, none can rival in terms of renown I. Newton's three laws. They can be formulated as follows:

1) An object in motion stays in motion unless acted on by a force. This is the law of inertia.

2) The magnitude of an object's acceleration is proportional to the net force and inversely proportional to the mass of the object.

3) For every force there is an equal and opposite force.

When it comes to mathematical axioms, the best known are probably those found at the beginning of the most celebrated textbook of all time, Euclid's Elements (here presented in Th. L. Heath's translation):

1) A point is that which has no part.

2) A line is breadthless length. 
3) The extremities of lines are points.

4) A straight line is a line which lies evenly with the points on itself.

5) A surface is that which has length and breadth only.

And so on.

These are called "definitions." A little further down, one finds the following "common notions," which are also axioms in a way.

1) Things which are equal to the same thing are also equal to one another.

2) If equals be added to equals, the wholes are equal.

3) If equals be subtracted from equals, the remainders are equal.

And so on. In his Elements, Euclid distinguishes between "definitions" (Greek horoi), "postulates" (Greek aitemata), and "common notions" (Greek koinai ennoiai). They can all collectively be called "axioms."

\subsection{What Is the Difference between a Physical Law and a Mathematical Axiom?}

The short answer is as follows: Physical laws are inductive, whereas mathematical axioms are deductive. The question arises: What is inductive and what is deductive? Before considering this question, first this.

In order to understand the brain's OS, and build an artificial intelligence that thinks exactly like us, nothing is more important-I believe-than to consider the theory of the brain's OS as a theory of physics, not a theory of mathematics, not a theory of psychology, not a theory of cognitive science, not a theory of philosophy, not a theory of computer science, not a theory of logic, and so on.

Then again, there is so much mathematics in theories of physics. The theory of the brain's OS is no exception. It is important, however, to realize that the mathematics supporting the physical theory of the brain's OS is not the familiar mathematics of the physics of mass and motion. In the physics of mass and motion, quantity is everything, involving both increase and diminution, and hence calculus plays a crucial role because it describes rates of change in quantity.

The attention that G. Boole's new and different mathematics has attracted, especially in this age of computer science, has detracted attention from the fact that G. Boole's theory is a theory of physics. It does not help that G. Boole himself did not think of his theory as a theory of physics.

Because the theory of the brain's OS is a theory of physics supported by its own mathematics, it needs to exhibit both physical laws and mathematical axioms.

But what is the difference between a physical law and a mathematical axiom?

In principle, the laws of physics are part of inductive reasoning. They are inferences drawn or derived ("induced") from repeated observation of physical nature. It also follows that they are not immediately obvious. Repeated observation is necessary. Consider the laws of gravity. It took many centuries of observation to properly formulate them. In addition, laws of physics are only probable and never $100 \%$ certain. Who knows what gravity is? One has every reason to believe that, deeper down, there is a more fundamental truth. 
By contrast, mathematical axioms are part of deductive reasoning. They serve as premises, starting points, that no one could possibly question. Next, axioms are combined into theorems.

Physical laws are obtained from many observations over a long time. By contrast, mathematical axioms should be immediately apparent. Consider the so-called commutative property evidenced by, say, $a+b=b+a$. There is no need for extensive observation of physical nature to establish that this must be true.

Another example is the mathematical axiom that equals added to equals produce equals. Consider two containers each containing a liter of milk. Is it really necessary to conduct extensive experiments to establish that adding a liter of milk to either container will amount to the same amount of milk in both containers? There is no need for repeated observation of physical nature to establish the validity of this axiom. It is immediately apparent. What is more, axioms combined with axioms can produce theorems. Theorems are just strings of axioms. Theorems are not produced by repeated empirical observation. They are deduced from the axioms.

But what about the relation of mathematical axioms with physical nature? While they may not be derived from repeated observation of physical nature, they evidently do not contradict physical nature. How could they after all?

There have been many efforts to define the foundations of mathematics. These foundations have not been found. There is no doubt that mathematics works. There is something magical about it, as it were. But it is not presently possible to understand why mathematics works, if it ever will be. What matters presently is that the methods of physics and mathematics are different. But they are also complementary. It is not possible to do physics without doing mathematics. Then again, it is possible to do mathematics without doing physics. The contrast between physics and mathematics is one thing. But the deeper contrast is between inductive and deductive thinking.

Before defining what some of the laws and the axioms of the brain's OS are, three properties of physical theories may be highlighted.

\subsection{The Physics of the Brain's OS: Wherever There Is Physics, There Is Mass}

I have elsewhere, in my afore-mentioned Prolegomena to the Complete Physical and Mathematical Theory of Rational Human Intelligence (2015) published by www.scirp.org, also the publisher of this journal, tried to detail the physical nature of rational human intelligence. This is not the place for a full review. Still, it may be useful to present a self-sufficient outline.

What is physical and what is mathematical about the theory of the brain's OS? It is not always easy to separate the two, not even in the physics that everyone thinks of as physics and learns in school as physics. And yet, the distinction is real and undeniable.

The same distinction applies to the theory of the brain's OS. This theory is not 
a pure theory of mathematics as G. Boole more or less assumed. That assumption may serve as an obstacle to truly comprehending what the theory of the brain's OS really is.

But what quintessentially makes the theory of the brain's OS a theory of physics with its own mathematics rather than a theory of mathematics or, for that matter, a theory of just about anything else?

The fundamental fact is that theories of physics are concerned with what is called mass. The first thing to know about mass is that no one, even physicists, knows what mass deep down is. There is so much that we know about mass. But no one really knows what it is. Still, people know to recognize it for what it is.

All of human life revolves around inhabiting a human body that is endowed with a certain mass and engages other masses.

\subsection{Central Place of Mass in Physics}

Physics is about more than mass. Then again, everything else seems to be a property of mass. One cannot consider most anything else without also considering mass. Mass occupies a key position. It will therefore come as no surprise that it also does in the theory of the brain's OS. How so will be discussed below.

As regards the central position of mass, just consider the seven base units according to the International System of Units (SI). All the other units can be formulated in relation to the base units. The seven base units are as follows:
1) mass,
measured in kilograms $(\mathrm{kg})$
2) space,
measured in meters $(m)$
3) time,
measured in seconds $(s)$
4) electric current,
measured in amperes $(A)$
5) temperature,
measured in kelvins $(K)$
6) amount of mass,
measured in moles $(\mathrm{mol})$
7) luminous intensity,
measured in candelas $(c d)$

What is most immediately apparent to the brain and also studied first in physics classes is the first three. Together, they constitute the physics of mass and motion. No one really knows what space and time are. But covering a certain distance in space in a certain amount of time constitutes speed.

Mass combines with space and time to produce the concepts of

1) momentum, 2) force, 3) energy (potential for work) or work (itself), and 4) power, whose units are combinations of the first three units, $\mathrm{kg}$, $\mathrm{m}$, and $\mathrm{s}$, namely the following:

1) $\left.\mathrm{kg} \cdot \mathrm{m} / \mathrm{s}, 2) \mathrm{kg} \cdot \mathrm{m} / \mathrm{s}^{2}, 3\right) \mathrm{kg} \cdot \mathrm{m}^{2} / \mathrm{s}^{2}$, and 4) $\mathrm{kg} \cdot \mathrm{m}^{2} / \mathrm{s}^{3}$.

Number 4) and number 5) can be seen as properties of mass. Number 4) relates to how a mass can be electrified or charged and exhibit related phenomena. Number 5) relates to how mass can become colder or warmer. Both are related to the first three in that electricity and heat can produce a force, as expressed by $\mathrm{kg} \cdot \mathrm{m} / \mathrm{s}^{2}$. When this force is generated over a certain distance, it does what is called work, as expressed by $\mathrm{kg} \cdot \mathrm{m}^{2} / \mathrm{s}^{2}$. 
Number 6) is just a way of quantifying mass in terms of how many little particles, atoms and such, it contains. One mole (mol) of mass contains about 6.02 $\times 10^{23}$ particles.

But it is number 7), luminous intensity, that is the most interesting in the present analysis, which concerns the study of rational human intelligence as a physical phenomenon.

\subsection{Luminous Intensity as Part of a Theory of Physics Involving the Brain through the Senses, Like the Theory of the Brain's OS}

As a theory of physics, and as distinct from other theories of physics, luminous intensity is most strikingly similar to the physical theory of rational human intelligence. The reason is that neither exists without a connection to the brain through the senses. The human body is an inextricable component of the theory.

In the case of luminous intensity, the sense that serves as a conduit to the brain is sight through the eye. In the case of rational human intelligence, all senses can serve as a conduit. But sight clearly appears to be by far the main conduit.

Luminous intensity is part of the discipline of photometry, which is Greek for "measuring light." Importantly, photometry measures light as perceived by the brain through the human eye. Photometry is distinct from radiometry, which is concerned with the measurement of all kinds of radiation including light independently of human vision and the human brain.

In the case of both luminous intensity and rational human intelligence, the brain organizes itself as the result of impulses received from physical nature or mass. In the case of rational human intelligence, all the senses can play a role. And there are many more than the classical five senses. Some come from mass outside the body, like feeling the wind blow or the sun heat up on one's face. Some come from inside the body, like feeling hungry and feeling dizzy.

In both cases, this organization can be described in the language of mathematics. But there is a difference.

In the case of luminous intensity, the mathematics is quantitative, that is, mathematics as everyone knows it. Things get bigger and smaller. In the introduction to his Elements of Algebra, perhaps the second most popular textbook of all time after Euclid's Elements, L. Euler states that mathematics is the study of all that is capable of increase or diminution. That is only half the truth. Since G. Boole, there is a fully developed non-quantitative mathematics, as evoked by the title of my 2008 book, The Other Mathematics [4].

In the case of luminous intensity, the phenomenon of physical nature that causes the brain to organize itself has everything to do with light as a property of physical nature and its intensity, which can increase or decrease.

But what is the property of physical nature that causes the brain to organize itself into the structure called rational human intelligence? 


\subsection{Conclusion (1): The Physical Laws of the Brain's OS}

There are many laws of traditional physics and quite a few ways to organize them. The best-known laws of traditional physics are I. Newton's three laws.

As regard the brain's OS, suffice it to present one principle and two laws as most fundamental. They are in fact closely paralleled by the traditional laws of thought. Accordingly, there is much that is intuitively correct in the three main traditional laws of thought.

Physical laws pertain to mass. The fundamental principle of mass is the contrast between what a mass is, as determined by its attributes, and what it is not. This closely corresponds to the traditional Law of Identity, namely

A cow is a cow (or also: a Cow! that is, not not a cow).

But it is two fundamental laws that provide the brain's OS with a firm grip on physical reality.

The first law provides universality. The law states that, in as far as the brain's (limited) grasp of reality is concerned, what something is and what something is NOT adds up to everything thinkable, leaving nothing whatsoever out. This law closely corresponds to the traditional Law of the Excluded Middle, namely

Something is either a cow or not a cow. There is no third possibility.

The second law provides sharpness. The law states that, in as far as the brain's (limited) grasp of reality is concerned, nothing is both something and NOT that same something at the same time. The dividing line is razor sharp. This law closely corresponds to the traditional Law of Contradiction, namely

Something cannot at the same time be a cow and not a cow.

I refrain from further detail at this time.

\subsection{Conclusion (2): The Mathematical Axioms of the Brain's OS}

The "Laws of Thought" of G. Boole's 1854 book are in fact mathematical axioms and he even calls them that. They are not properties of physical laws but properties of the way in which the brain views the physical world. Three examples may suffice.

The first is the axiom of commutativity, that is

$x$ AND $y=y$ AND $x$,

$x$ OR $y=y$ OR $x$.

Indeed, selecting what is both sheep and white is the same as selecting what is both white and sheep. Or selecting whoever is either French and a doctor is the same as selecting what is either French or a doctor. The order does not make any difference. The axiom is not physical because there is no natural order in physical reality. Choosing a specific order is a product of the mind.

The second axiom is that of idempotence. G. Boole considers it the most fundamental axiom. It is states that

$x$ AND $x=x$. Or: $x x=x$.

An example is as follows. If one considers all that is both French AND French, that still adds up only to what is French.

By contrast, in quantitative mathematics, the following is valid: 
$x \boldsymbol{x}=\boldsymbol{x}^{2}$.

The third axiom also involves idempotence, but G. Boole does not discuss it. It is the fact that

$x+x=x$.

In other words, if one adds the French to the French, one still only obtains only the French.

By contrast, in quantitative mathematics, the following is valid:

$x+x=2 x$.

\subsection{Excursus: Absence of Complete Entropy as Enabler of Rational Human Intelligence}

According to the Second Law of Thermodynamics, entropy always naturally increases without some external influence. Entropy is more or less something like disorder. The analogy often used is that the objects inside a house will over time become more and more disorganized, with everything eventually ending up out of place. Unless one does something about it. But that is external influence. The most striking characteristic about this comparison is that everyone knows that the stuff inside one's home never rearranges itself into a certain order all by itself.

Accordingly, the eventual outcome of the Second Law of Thermodynamics is that the universe will turn into a continuum of chaos in which everything, all that is mass, looks the same and the entire universe is very cold. Thus, a maximum of entropy will presumably be achieved.

But for now, mass is organized in the universe. Each mode of organization causes a certain amount of mass to be different from all other mass in countless ways. That certain amount of mass is typically divided into discrete entities or things that exhibit that kind of organization. For example, certain entities of mass organize into what is called a tree. Certain entities organize into what is green in color.

It is this absence of complete entropy and the concomitant presence of organization that makes rational human intelligence possible.

\section{Physics versus Mathematics in the Study of the Brain's OS: Function of the Four Key Mathematical Operators NOT, AND, OR, and IS}

\subsection{Introduction}

The known theories of physics are generally concerned with properties that apply to all mass, though in different quantities. Just consider gravity and electrical conductivity. The theory of the brain's OS is different. It is concerned with discrete amounts of mass that exhibit one or more distinctive features or attributes that set them apart from all else that is mass.

In what follows, the distinction between physics and mathematics in relation to the brain's OS is further illustrated by means of the relation of the four key 
mathematical operators NOT, AND, OR, and IS to physical reality.

\subsection{The Physics and Mathematics of NOT (Contrast Digitality)}

What can one say about a single feature or attribute and mass? All entities of mass that exhibit a certain feature or attribute are contrasted with everything else that is mass. For example, all that is a tree is contrasted with all that is not a tree. That much for physics, involving properties of physical nature independent of the brain but also as they appear to the brain without any intervention on the part of the brain.

It is the prerogative and privilege and initiative of the brain to focus either on all that is a tree or all that is not a tree. This is where the matter turns mathematical. The focus on either what is a tree or not a tree is not part of physical nature. It is a function of the brain. And towards exercising that function, the brain makes use of the mathematical operator NOT. The operator even makes it possible for the brain to focus on what is NOT NOT a tree, as in "a tree!" (and not something else, that is, not not a tree). To physical nature itself, the difference between a tree and not not a tree is irrelevant. It only has reality in the brain. What is needed to express the difference is the mathematical operator NOT. And that operator resides in the brain. The operator is therefore mathematical. That is the difference between the physics and the mathematics of the brain.

This much for the physics and mathematics of the distribution of a single feature or attribute across entities of mass. But what about two or more features or attributes?

\subsection{The Physics and Mathematics of AND and OR (The Two Mathematical Modes of Selection Digitality)}

As regards the distribution of features or attributes across entities of mass, it is not the case that each entity of mass is characterized by one feature and that all entities are differentiated from one another by their own single feature or attribute that is unique to them. The distribution of features or attributes across entities or things is of quite a different kind: A single entity may exhibit more than one feature and two or more entities may share the same feature.

To generate rational human intelligence, the brain selects entities for attention and focus on the basis of their features or attributes, whereby each attribute outside the brain is represented by a sign stored inside the brain that makes reference to the attribute. The use of the sign inside the brain selects the attribute and therefore the entity that exhibits it outside the brain.

When only one sign is used by the brain to select one attribute and therefore the entity associated with the attribute, the mathematical operator NOT makes it possible to select all the entities that do not exhibit the attribute in addition to those that do. There are two (2) selections. One might add the double use of NOT as a third or as a special case of NOT.

In the case of two or more attributes, the attributes in conjunction with the 
operator NOT characterize $2^{x}$ types of theoretically possible physical entities. Consider the case of two attributes of entities, say "French" and "doctors." There are $2^{2}$ or 4 sets of entities: 1) what is French and a doctor, 2) what is French but not a doctor, 3) what is a doctor but not French, and 4) what is not French and not a doctor. Again, the mathematical operator NOT allows the brain to focus on entities in terms of attributes that they do not exhibit.

What happens when the brain uses two or more signs to select entities for attention or focus? Consider the case of two signs inside the brain referring to two attributes or entities outside the brain. An example is "French" and "doctor," this time as English words that are stored as signs inside the brain.

It is not possible for the brain to just produce the two signs "French" and "doctor" and make sense. The reason is that a necessary choice imposes itself between two, and only two, options. The two signs inside the brain need to be confronted with physical reality outside the brain. The physical reality is that there are four classes of entities listed above.

Which of the four classes of entities listed above exhibit the two attributes "French" and "doctors"? Clearly, one finds them in three classes, 1), 2), and 3). Focusing on these three classes allows the brain to capture all that is "French" and "doctor." However, there is one other striking inescapable way for the brain to look at physical reality. Empirically speaking, there is no denying that some entities, namely those of class 1), exhibit both attributes.

There are therefore mathematically two and exactly two ways of selecting both French and doctor, 1) united in single entities and 2) distributed across entities. The two mathematical operators are AND and OR. The operator is often expressed by mere juxtaposition, as in "French doctors," that is, "anyone who is French and a doctor."

This much about the two sole mathematical ways of selecting entities by means of two or more signs in the brain from all possible combinations of entities. More detail is found in my Prolegomena. However, a much more extensive analysis remains desirable, resulting in a complete mapping of Selection Digitality.

What is perhaps most important to realize is that it is a selection of entities on the basis of two or more attributes, involving the mathematical operators AND and OR in conjunction with the operator NOT. The result of this selection is a single class of entities. By contrast, Contrast Digitality (see above) pertains to only one class of entities and the ability to choose between selecting an entity on the basis of what it is or what it is not.

The present section is concerned with the physical reality of the distinction between attributes distributed across entities (including sometimes united in a single entity) and attributes united in entities. The selection of one or the other is not a property of physical reality. It is a brain event. Still, physical reality imposes on the brain a choice between selecting entities as distributed and entities as united. The two operators AND and OR came into existence in the brain to make this choice possible. 
The operators AND and OR are mathematical because they are universal and they constitute a fully closed system in which all cases can be considered. There are only two cases. But they are not part of pure mathematics. That is because they owe their mathematical structure in part to specific properties of physical nature, that is, mass.

Selection Digitality makes it possible for the brain's OS to select a single set of entities on the basis of more than one attribute. For example, four selections are possible on the basis of the two attributes "French" and "doctor."

Incidentally, there is no way of selecting just features independent of entities, though G. W. Leibniz seemed to think so. I refer to my Prolegomena for more detail on G. W. Leibniz's view, definitively rejected by J. Venn. G. W. Leibniz would subtract the attribute "rational" from "human being" and obtain "animal." That is possible in philosophy. But in the mathematics of the brain's OS, the result of subtracting "rational" from "human beings" is no doubt "irrational human beings." If one subtracts anything from "human beings," it has to be a subset of human beings because one is subtracting entities from a previously stated set of entities. The theory of the brain's OS is a physics theory. Mass and its properties play a fundamental role.

There are some who think, typically German scholars, that G. W. Leibniz's work is the foundation of the analysis of rational human intelligence. G. W. Leibniz did think in the right direction. But in fact, J. H. Lambert saw more than G. W. Leibniz and more than anyone else before G. Boole, as J. Venn has pointed out. Yet, J. H. Lambert did not formulate a totally comprehensive theory in the way that G. Boole did.

Selection involves all possible combinations. But what if not all possible combinations exist? It would be natural for the brain to want to convey the fact.

\subsection{Physics and Mathematics of the Brain's OS beyond AND and OR (Selection Digitality)}

The mathematical operators AND and OR supplement one another $100 \%$ in allowing the brain to select one (1) entity on the basis of two or more (2+) attributes.

Consider, for example, just two (2) attributes A and B. By using just the mathematical operator NOT, four (4) possible classes of entities can be distinguished in relation to these two attributes: 1) what is both A and $\mathrm{B} ; 2$ ) what is $\mathrm{A}$ and NOT B; 3) what is B and NOT A; and 4) what is NOT A and NOT B.

While the mathematical operator NOT establishes four classes as the playing field for two attributes, the brain's OS cannot contemplate any of these four classes without choosing to connect the two attributes in one of exactly two ways by means of either the operator AND or the operator OR, as was noted above. The operator NOT, which exists by virtue of the fundamental principle of physical reality from which all rational human intelligence is derived, does not suffice.

Consider class 1), what is both A and B, listed above. When the brain selects a 
certain class of entities based on these two attributes, the choice is between 1) A AND B and 2) A OR B. Choice 1) is more typical. Accordingly, there is no need to use AND in "French doctors." But "or" is mandatory in "French or doctors."

But AND and OR can become ineffective in certain cases. Consider the two attributes "Belgian (citizens)" and "European (citizens)." At face value, neither "Belgian AND European" nor "Belgian OR European" are meaningful.

The reason is that Belgians are all Europeans. This means that of the four classes generated by the two attributes and the operator NOT, one does not exist or is empty, namely "Belgian and not European."

As a result, "Belgian AND European," or "Belgian Europeans," refers to the same class of entities as just "Belgian." "European" does nothing to reduce the class of Belgians because none of them is not European. Compare this to "French AND a doctor" or "French doctors." "Doctor" reduces the class of the French because some French are not doctors.

Also, as a result, "Belgian OR European" refers to the same class of entities as "European." "Belgian" does nothing to add to the class of Europeans because they are already all Europeans.

The opportunity presents itself again to illustrate two sharp distinctions that apply to the theory of the brain's OS. First, it involves both physics and mathematics. Second, the mathematics in question is not pure mathematics but mathematics as applied to physics. It is also possible again to illustrate the ubiquitousness of the fundamental physical principle of mass from which the entire theory is derived, the contrast between what entities exhibiting a certain characteristic are and what they are not.

Theoretically, two attributes involve four classes of entities. In the case of "Belgian Europeans" and "French doctors," two corresponding classes are "Belgians that are NOT Europeans" and "French that are NOT doctors." They are mathematically the same. But they are physically different. Note the presence of the operator NOT.

This is where the difference between physics and mathematics makes itself felt. Physically speaking, non-European Belgians do not exist. Therefore, the selection "non-European Belgians" is purely mathematically possible but not meaningful on physical grounds. By contrast, non-French doctors do exist physically. Therefore, the mathematical selection "French doctors" makes sense.

In its efforts to get a grip on physical reality, the brain's OS meets an obstacle with AND and OR. The obstacle is that neither AND or OR (Selection Digitality) can signify that certain classes involving two classes do not exist. The need is for an additional operator expressing an additional type of digitality.

That additional operator is IS. The additional type of digitality is Nexus Digitality.

\subsection{The Mathematical Operator IS (Nexus Digitality): Three Differences with AND and OR (Selection Digitality)}

There are three (3) key differences between the mathematical operators AND 
and OR, on the one hand, and the mathematical operator IS, on the other hand. The first two pertain to number.

1) Two vs. Two or More (Attributes)

AND and OR involve two or more (2+) attributes. An example of four (4) attributes linked by AND is "many big white sheep."

IS is limited to two (2) attributes. Rational human intelligence has evolved in such a manner that the brain's OS cannot produce something like "Aristotle IS a philosopher IS Greek." IS is always a nexus between two attributes. If there is a third attribute, then a second, independent nexus is needed.

There is no binding reason why rational human intelligence could not have evolved to make a double nexus in a single statement possible. The fact is: It did not.

2) Two vs. One (Classes of Entities)

AND and OR yield one (1) class of entities, such as "French AND doctors" and "French OR doctors."

IS is all about two distinct classes of entities, such as "Belgians" and "Europeans," and the relation between them, as in "Belgians are Europeans."

3) Description vs. Selection

From the perspective of what the brain does, the brain activity involved in the complementary operator pair AND and OR is radically different from that involved in the single operator IS. Such is the nature of the brain's OS.

Both are concerned with contemplating entities in light of two-in the case of AND and OR, two or more-entities. The brain activity involved in AND and OR can best be described as selecting. The brain activity involved in IS can best be described as describing.

\subsection{The Mathematics of the Operator IS (Nexus Digitality)}

The function of the mathematical operator IS is to convey the non-existence of a class or classes as it affects the relation between two, and exactly two, entities.

Two attributes generate four classes. Therefore, theoretically speaking, there would appear to be five (5) options: the number of existing classes can be 4, 3, 2, 1 , or none (0). Accordingly, the number of classes being eliminated would be 0 , $1,2,3$, or 4 .

As J. Venn first demonstrated, drawing two overlapping circles representing the two attributes A and B is eminently useful. The two circles create four compartments and each compartment can either be empty or full.

Two (2) of the five (5) options can readily be eliminated.

First, if the existing classes are four (4) in number, no class is being eliminated.

Second, one of the five options is physically and therefore mathematically impossible, namely zero (0) existing classes or eliminating all four (4) classes. How so?

According to a physical law of the brain's OS (see below), the set of all entities 
exhibiting a certain attribute and the set of all entities not attributing it together add up to all that is thinkable, the universe of thought. Consider an attribute A. All that is A and all that is not A add up to everything. Therefore, if A does not exist, then not-A is everything. The same reasoning applies to two or more attributes. But eliminating both $\mathrm{A}$ and non- $\mathrm{A}$ results in a contradiction.

That leaves three (3) options. Two of them are together by far the most common. In the first of the two, one of four classes is empty and three classes are full, as in "Aristotle is a philosopher." The empty class is characterized by the attributes "Aristotle" and "NOT a philosopher." In the second of the two, two classes are empty and two full, as in "Paris is the capital of France." The two empty classes are characterized by the attributes "NOT Paris" and "NOT the capital of France"; the two full classes, by the attributes "Paris" and "the capital of France."

That leaves the third option in which three classes are empty. The case in question would seem to be rare. Consider the two attributes "free" and "obtained without effort." The statement "Nothing is either free or obtained without effort" leaves only one class full: everything is both not free and not obtained without effort.

\section{A Sixth Flavor of Digitality: Existence Digitality}

\subsection{The Mathematical Operator THERE IS}

In my Prolegomena [1], I proposed that the blueprint of the brain's OS contains five digitalities: Contrast Digitality, Selection Digitality, Nexus Digitality, Supplement Digitality, and Certification Digitality.

But there is need for a sixth type, which I earlier classified together with Nexus Digitality. It may be called Existence Digitality.

Nothing is more characteristic of the more than two-thousand-year old history of the study of traditional logic than the distinction between universal propositions and particular propositions. The distinction has been universally accepted. They can be both affirmative and negative. The universal affirmative is

All A is $\mathrm{B}$.

The universal negative is

No A is $\mathrm{B}$.

The particular affirmative is

Some A is B.

The particular negative is

Some is not $\mathrm{B}$.

J. N. Keynes's Studies and Exercises in Formal Logic (fourth edition, 1906) is still useful as a comprehensive survey of this $2000+$ year history.

The status of the four types was cemented by their role in the syllogism. The following well-known example of a syllogism contains three universal affirmatives.

All human beings are mortal. 
Socrates is a human being.

Therefore, Socrates is mortal.

Thousands and thousands of pages have been written over the course of more than two thousand years about the syllogism. But what matters presently is not the syllogism. It is the notion that universal statements and particular statements are counterparts, two subtypes of the same species. Even G. Boole could not resist this notion and tried to make sense mathematically of universal propositions in the same way as he made sense of particular propositions.

By contrast, it will be proposed here that universal statements and particular statements are not two subtypes of the same species but two entirely different species. To my knowledge, the only person ever to hold such a view is J. Venn in his Symbolic Logic (second edition, 1894, 179-197).

The theory of the brain's OS is physical and mathematical. It follows that the difference between universal and particular propositions needs to be formulated in physical and mathematical terms. In that regard, the difference is simply this. Universal propositions involve the mathematical operator IS. Particular propositions do not. This is also J. Venn's position. But is not G. Boole's. No one ever understood G. Boole better than J. Venn.

The present writer was inspired by J. Venn when it came to extracting oneself from a distinction that is so universally accepted. This is especially important because J. Venn deeply admired G. Boole, and yet radically broke with him when it comes to particular propositions.

J. Venn considered the treatment of universal propositions "comparatively easy" (p. 179). The mathematical operator IS has been described at length in the previous section. But when it comes to particular propositions, J. Venn rightly opined that "[i]t would not be too much to say that their adequate representation has proved a vexation to most thoughtful symbolists" (p. 179). In fact, it is difficult to find two students to agree on the interpretation of particular propositions.

J. Venn has apparently been a voice crying in the desert in the vast literature on logic. The time has come to translate his approach into strictly physical and mathematical terms.

What do particular statements do?

Consider the statement

Belgians ARE Europeans.

Denying the existence of the class of Belgians that are not Europeans. Then compare this statement with

French people ARE Europeans.

Generally speaking, this latter statement is more or less true.

But one might object. Some French subjects live in overseas territories that are not in Europe. This means that there do exist French people that are not Europeans. The need therefore arises for the brain's OS to be able to articulate, physically and mathematically, that a class actually exists. This is not something that the four mathematical operators NOT, AND, OR, and IS can do. There is need 
for a fifth mathematical operator.

The operator IS involves two (2) different classes of entities. By contrast, the desired fifth operator must pertain to just one (1) class of entities characterized by two attributes. Like the new fifth operator, the operators AND and OR pertain to one class of entities.

The operators AND and OR select one (1) class. The operator IS describes or makes a statement about the relation between two (2) classes. The new fifth operator ought to do both. It selects a class on the basis of two attributes and then makes a statement about it.

What is this fifth mathematical operator?

Consider the statement

The cats are in the house.

This statement eliminates the class of cats that are not in the house. Next consider the statements

Cats are in the house

and

$A$ cat is in the house.

There is no denying that this statement seems incomplete. The natural inclination and strong compulsion will be to state

There are cats in the house

and

There is a cat in the house.

These two statements do not contain the operator IS. There are three problems with the use of the operator IS in "Cats are in the house" and "A cat is in the house."

First, one task of the operator IS is to eliminate one or two classes. But all four classes exist:

1) Cats in the house;

2) Cats not in the house;

3) Anything else but cats in the house;

4) Anything that is a cat and is at the same time outside the house.

It is therefore mathematically impossible to use the operator IS. Because IS eliminates a class. And no classes are being eliminated in "Cats are in the house."

Second, another task of the operator IS is to relate two classes of entities to one another. An example of two classes of entities is "cats" and "things that are in the house," amounting to four classes when including their two supplement classes. In the statement "The cats are in the house," "the cats" in question are an integral part of the "things that are in the house." But in "Cats are in the house" there is no such special relation.

Third, the focus of "A cat is in the house" is on one class and not two.

It is an undeniable fact that one typically does not make statements like "A cat is in the house" or "Cats are in the house." Nothing is more natural for the brain's OS to produce instead "There is a cat in the house" and "There are cats in the house." The obvious interpretation is that the brain's OS expresses the exis- 
tence of one class of entities: cats that are in the house. J. Venn represents this mathematically as ">0," that is, "is larger than zero."

But there is another way of solving the problem inherent in the formulation

"Cats are in the house," namely by stating

Some cats are in the house.

This is an example of the particular proposition, which is omnipresent in doctrine on syllogisms in traditional logic.

\section{2. "Some" as a Component of the So-Called Particular Proposition}

The meaning of "some" has been discussed interminably over many centuries in countless treatises of logic. As was noted above, J. Venn already took a decisive step away from more than two thousand years of interpreting particular statements as a kind of counterpart to universal statements.

He introduced the mathematical notation " $>0$," that is, "is more than nothing" or "exists." It may be assumed that he would represent a statement such as "Some cats are in the house" with this same notation.

This is where the present line of argument departs from J. Venn's. "Some cats are in the house" is mathematically different from "There are cats in the house." The first statement undeniably contains the operator IS. In that regard, the statement

Some cats are in the house

may be compared to

Five cats are in the house;

A number of cats are in the house,

Some well-defined cats are in the house.

And so on.

The reference is to a well-defined group of cats. The operator IS functions to include this entire well-defined group into the class of things that are in the house and implies the non-existence of anything that at the same time belongs to the group.

In some way, the statement "Some cats are in the house" can be rendered as "As for some cats, they are in the house."

Another way of looking at the matter is that "some" can stand in in a general way for any attribute without defining it.

In that regard,

Good people go to heaven.

has the same digital structure as

Some people go to heaven.

It is possible to know about "good" without saying so.

Particular "some" of traditional logic should be distinguished from G. Boole's representation of what is completely indefinite, namely $\frac{0}{0}$. This can be none, some, or all. "Some" can be quite definite. One just does not say what it is. 
The matter is just slightly complicated because "some" can also be an equivalent of a plural indefinite article, which English does not have. In that regard, "I saw some people there" means more or less the same as "I saw people there." In that case, "some" is preceded by mathematical operator THERE IS, as in

There are some cats in the house.

In conclusion, "There are (some) cats in the house" is an expression of Existence Digitality whereas "Some (specific) cats are in the house" is an expression of Nexus Digitality.

\section{Three Properties of Physical Theories}

Rational human intelligence propagates physically through the brain located under the skull in accordance with physical-mathematical laws and axioms just as force propagates physically through a car engine located under the hood in accordance with physical-mathematical laws.

As a physical theory, the theory of the brain's OS shares three properties with other theories of physics: 1) it combines inductive and deductive thinking; 2) it does not describe ultimate causes of physical realities; 3) it appeals to intuitive ways to comprehend a reality whose deeper causes are unknown.

First, theories of physics are the result of a combination of observation and experimentation, on the one hand, and mathematics, on the other hand. It is not always fully clear where the observation ends and the mathematics begins. But it is useful to differentiate between a physical theory and a purely mathematical theory. G. Boole thought of the theory of the brain's OS more as the latter. But it is the former. And he created the mathematics that it needed. This act of creation may have biased his own view that what he was doing was mathematics.

Second, theories of physics do not describe final causes and, as J.-L. Lagrange always emphasized, one should not try to find those final causes. The theory of the brain's OS is interesting in this regard because even the intermediate causes are not known at this time. The intermediate causes are the workings of the brain under the skull. It is like looking under the hood of a car. Theories of physics describe the propagation of force and electricity in a car engine. But one still needs to look under the hood of the car to observe the mechanics. Likewise, the theory of the brain's OS explains how rational human intelligence propagates through the brain. How this happens mechanically under the skull is another matter. But even when that is discovered, the final causes of how the brain processes physical reality around itself will probably remain just as obscure as physical reality itself is.

Third, because the final causes remain unknown, theories of physics may sometimes need to rely on creative use of the human imagination to discover them in the first place and to make them more intuitively apparent. One is reminded of how fictional diagrams allowed J. C. Maxwell to formulate the complete physical theory of electromagnetism without even knowing what an electron is. Such use of the imagination may seem uncritical at first. But it is often helpful and sometimes even necessary. 
What better way of illustrating the use of imagination than by means of the physics of mass and motion, what everyone now understands as physics.

The gravitational force of attraction between two masses $m$ and $M$ is proportional to the product of two masses, that is, $m \times M$. The larger the masses, the bigger the attraction. But why not proportional to the sum of the two masses, $m$ $+M$ ? Experimentation confirms that it is the product. But are there intuitive ways of making clear that it is the product? Consider two masses of size 3 (whatever the unit of mass). If one doubles either mass to 6, the force of attraction increases as 6 relates to 18 , that is, $6 \times 3$, and not as 6 relates to 9 , that is, $6+$ 3. Why?

One might imagine both masses of 3 divided but not separated into three masses of 1 . It is easy to imagine that each single mass of 1 in $m$ attracts each of the three (3) masses of 1 in $M$ for a total of three (3) forces of attraction. The result is nine $(9)$ forces of attraction, or $3 \times 3$. It makes sense, therefore, that the size of attraction is proportional to the product of the masses. Therefore, if one doubles either mass to 6 , the force is now 18 , that is, $6 \times 3$.

This use of the imagination and intuition does not reveal the final cause of gravitation. But an important lesson can be derived from it for the formation of theories in general.

One more example. High school students are taught that the force of gravitational attraction is "inversely as the square of the distance." In his celebrated Christmas lectures of 1859-1860, published under the title The Forces of Matter, M. Faraday called this description "a sad jumble of words until you understand it” (p. 22). Many students of physics in high school and beyond may wonder: Why the square? It is not really immediately obvious and it took a long time to figure out. I. Newton even got into a bitter dispute with R. Hooke who claimed priority regarding the insight. Yet, I. Newton did acknowledge R. Hooke in his Principia Mathematica.

The final cause of this proportional relation is unknown. It is upon the imagination to make sense of it in an intuitional and transparent manner.

One way of doing it is in three steps.

First, the relation is proportional. It is not about one distance $r$, as the expression $\frac{m M}{r^{2}}$ seems to suggest according to I. Newton's Second Law, but about a proportion between two or more distances. That means that, if $r$ is multiplied by 2 , the force is decreased by $2^{2}$. It is necessary to compare two (2) distances to understand the square proportion.

The second step involves an insight provided by $M$. Faraday in the above-mentioned source. He uses light instead of gravity. In any event, gravity can be considered to radiate, for lack of a better word, through space from the center of a mass. Again, it is not really known what gravity is and how it propagates. One would think that it needs to propagate through something. Could it be the much vaunted dark matter that no one has ever seen? What else could it be? 
As the propagation of gravity, there are three dimensions in space as the human mind is imagining it. One dimension, away from the mass producing a force of gravity, involves the direction of the force. The other two dimensions therefore must involve the size of the force. The force is like a two-dimensional "sail" propagating forward into space from a single point. And in each section of this "sail," gravity propagates with a certain intensity. How to evaluate the intensity?

How big is the "sail"? Presumably, it is infinite. It surely makes no sense that it stops somewhere. So the way to make sense of it is to cut out a square and see how that small portion gets bigger with distance. The result may then presumably be extrapolated to the entire infinite sail. Because there is no conceivable reason of imagining how it could not be.

Drawing two lines out from the center of the mass to both ends of one side of the square, it is easy to see how the side of the square doubles in size as the distance of the side receding from the center of the mass doubles. But that means that the square itself quadruples in size because the surface is equal to the side squared. That means, after doubling the distance, the same amount of radiating gravitation is now spread over a surface that is four times as large. It is therefore four times as weak because it is spread out over a surface four times as large. That is what distance squared means. Twice the distance becomes four times the square.

But there is a third step not considered by M. Faraday. His model works in only one direction. Gravitation between two masses $m$ and $M$ acts in two directions, from $m$ to $M$ and from $M$ to $m$, twice covering the distance. So should one not rather consider $2 r$ somehow rather than $r$ ? Perhaps this is immediately apparent to a professional physicist. But the need is for intuitive imaginations that immediately and attractively appeal to our shared common sense.

Why only $r$ and not $2 r$ ? The matter becomes clear when one joins the two masses $m$ and $M$ in the same place. They still propagate the same gravitation, now with greater force from the same point because they are joined together. Importantly, they now both do so over the distance $r$ and clearly not the distance $2 r$.

But perhaps the best example illustrating that intuition and imagination have a role to play when it comes to analyzing phenomena of which the final causes are unknown is the notion that two objects are generally considered to attract one another from their center of gravity. That is how all the calculations are performed. And the calculations do indeed concord with reality.

But obviously, nothing could be farther from the physical truth. Clearly, every component of a physical body is attracting any component of another physical body equally much. The fact that the attracting forces emanate from the center is a figment of the imagination. It cannot possibly be true. Then why does it work?

The need is for making intuitively clear why measuring the force of attraction from the center makes sense. 
Consider two perfect spheres attracting one another. Each little part of one sphere attracts each little part of the other sphere. Now it seems reasonable to assume that those parts of the two spheres that are closer to the other sphere as measured from the center attract the other sphere with greater force. Evidently, it is impossible to measure the countless forces in question. And there is no way of bringing two planets into a laboratory.

Then again, it seems reasonable to consider the two halves of the sphere separately. For each part of the one half of the sphere that is closer to the other sphere there is a corresponding part of the other half of the sphere that is farther. It may therefore be assumed that the two average out at the middle. The distance from the middle one sphere to the middle of the other is just the same as the distance from the center of one sphere to the center of the other.

In sum, it may seem uncritical to rely on intuition. But when the final causes are obscure, it is necessary to find imaginative ways to make something clear to anyone interested in an immediately apparent way. It is an important lesson to be kept in mind when studying the physical theory of rational human intelligence.

In this regard, much is to be learned from M. Faraday, his pragmatism, his clarity, his realism, his no-nonsense. One wonders how many students of physics have an intuitive understanding of I. Newton's Second Law. Clearly, M. Faraday too wondered about it because he described the traditional understanding of it as a "sad jumble of words." M. Faraday's knowledge of mathematics did not go much beyond some trigonometry. And yet, his experimental work formed the foundation of the modern theory of electromagnetism, the only one of the four known forces of nature to be more or less fully explained.

M. Faraday's approach should bring benefits to the study of rational human intelligence. It requires a certain finesse to produce theories that work about phenomena whose final causes we cannot discern and some of whose immediate causes are not accessible because the workings of the brain are poorly understood.

It is interesting to note that M. Faraday was unschooled just like G. Boole, but not quite as much.

\section{Historical Notes}

\subsection{Aristotle}

\subsubsection{The "Firmest of All Principles"}

I briefly characterize Aristotle's position on the fundamental laws of thought. It is possible to find traces of all three later traditional laws of thought in Aristotle's writings. But Aristotle does not frame what is fundamental about thought as three laws. Rather, he repeatedly refers to a single fundamental principle or axiom of thought.

In Book IV (or Gamma, that is, "III", if one styles Book I as an introduction as in antiquity) of his Metaphysics, Aristotle more than once formulates a "first 
principle" or "starting-point" (Greek arkhê) or also "opinion" (doksa) to which he ascribes the following emphatic characterizations, here cited in order of occurrence [5]:

1) "The firmest of all first principles" (Greek pasōn... bebaiotatē tōn arkhōn);

2) "by nature the first principle of all the other axioms" (phusei... arkhē... tōn allōn aksiōmatōn... pantōn);

3) "the firmest of all principles" (bebaiotatè tōn arkhōn pasōn); and

4) "the firmest opinion of all" (bebaiotatè doksa pasōn).

This repeated insistence on the importance of a single principle makes one wonder whether Aristotle ever considered anything more important than this principle in his entire opus. What is this first principle in question?

Aristotle does not always formulate the principle in question in quite the same way. Perhaps the best known formulation is found at IV.iii.9-10. I would translate it as follows. It is this formulation that Aristotle characterizes with expression 1) cited above. It comes in two parts, as follows.

A single thing cannot at the same time possess and not possess the same attribute, all else being the same... Assuming that whosoever can both be and not be the same thing (that is, exhibit and not exhibit the same property) is impossible.

Simply put, something cannot be a cow and not a cow at the same time.

The following three formulations of the principle accompany the other three expressions listed above.

Expression 2) describes the following formulation:

[C] learly it is impossible for the same man to suppose at the same time that the same thing is and is not.

In regard to this formulation, I wonder whether the following translation is possible:

Clearly it is impossible that the same man is and is not the same thing (... ton auton einai kai mè einai to auto).

Expression 3) accompanies the following formulation:

We have just assumed that it is impossible at once to be and not be.

And expression 4) characterizes the following formulation:

$[O]$ pposite statements are not both true at the same time.

And there are yet other formulations. It is tempting to try and relate all the formulations to one another. From a historical perspective, it would be interesting to understand as exactly as possible what Aristotle meant and how he may have been influenced by others.

However, I believe that the deeper essence of the formulations and their relations to one another cannot be grasped without a purely physical and mathematical perspective. It is only in such a perspective that any axioms of thought can be fully appreciated. But such a perspective has only become possible since G. Boole. And to offer such a perspective has been the aim of what precedes in the present paper. 
All this does not mean that the physical and mathematical perspective proves Aristotle wrong. G. Boole's digital mathematics made Aristotle's logic complete and rigorous. In other words, Aristotle's fundamental axiom of thought survives alive and well in G. Boole's digital mathematics.

\subsubsection{Proof of the Principle?}

In addition to formulating the principle, Aristotle also states why it cannot be proven, as follows [6].

Some ask for proof, but only because they lack education. For not knowing of what one needs to seek proof and of what not shows lack of education. Proving everything is definitely impossible. One would just recede into infinity (in trying to prove everything by something else) and the final step would still be without proof.

This also indicates that Aristotle is mathematical in nature because axioms from which theorems are derived are the essence of mathematics.

It should not be possible to prove that axiom is an axiom. If that were possible, it would not be an axiom.

In the history of mathematics, there have been efforts to prove that an axiom is an axiom, that means, prove that something cannot be proven. The proofs can be complex. But it seems justified to be skeptical about the possibility of proving that something cannot be proven.

A lot has been made in recent decades about K. Gödel's Incompleteness Theorem, which states more or less that there is always something that one cannot prove in mathematics.

\subsection{Before Aristotle}

It is also tempting to look for traces of the fundamental axiom of thought in earlier Greek philosophers of the sixth to fourth centuries BCE. I have not been able to find a clear formulation of the axiom anywhere earlier.

Earlier Greek philosophers wrote much about being (something) and not being (something) and about becoming and the like. And some of the reflections in question do remind one of the fundamental axiom of thought in a vague way.

Clearly, these philosophers were looking for, and were indeed on to, something. But they could not quite put their finger on what it was that they were seeking. I believe that this is an acceptable and charitable interpretation of the fact that a good deal of what they wrote may seem obscure and at least some of it reads like gibberish.

Aristotle is apparently the first on record to formulate the fundamental axiom of thought with clarity. But as was said, it is only the advent of digital mathematics with G. Boole around the middle of the nineteenth century that would make it possible to formulate axioms of thought in a final way.

One philosopher who seemed to be looking in the right direction very early on is Parmenides ( $f$. first half of the fifth century BCE) of Elea near Naples in southern Italy, which was at the time colonized by Greeks. Many identify him as 
the originator of a line of thinking that would lead to the fundamental axiom of thought.

Plato (about 429 BCE-347 BCE), who greatly admired Parmenides, also seems to have assumed that one cannot attribute two opposite properties to a single entity in a single statement [7].

\subsection{G. W. Leibniz}

G. W. Leibniz (1646-1716) tries out various formulations to describe the "principle of contradiction" on at least two occasions [8]. I owe the references to G. Boole [9]. The formulations in question are as follows (translated from the French):

A proposition is either true or false, which itself contains two true statements (énonciations): one is that what is true and what is false are not compatible in a single proposition, or that a proposition cannot be true and false at the same time, the other is that the opposite of what is true and false are not compatible, or that there is no middle between what is true and what is false, or also that it is impossible for a proposition to be neither true nor false. Now, all this is possible in all imaginable particular propositions. And so on.

[The principle of contradiction] holds that, of two contradictory propositions, one is true, the other false.

There is again the temptation to relate the various definitions to one another, this time in relation to G. W. Leibniz's various definitions. However, G. W. Leibniz's rhetorical roundabouts cannot yield final formulations of axioms of thought.

Again, what is needed to obtain final definitions of any axioms of thought is a strictly physical and mathematical perspective. It was G. Boole's great merit to have provided such a perspective with the creation of his digital mathematics. As a consequence, the contemplation of any axiom(s) of thought came to be entirely divorced from philosophy. It became part of mathematics in the strictest possible sense.

\subsection{J. Locke and L. Wittgenstein on the Traditional Law of Identity}

At first sight, there is something meaningless about a statement such as "A cow is a cow." Yet, as has been demonstrated above, people make this kind of statement all the time. One hesitates to assume that people delight in making meaningless statements.

It has also been proposed that such statements give expression to what is most fundamental about the brain's OS. Nothing is more essential to how we think rationally.

Philosophers have on occasion discussed such seemingly tautological statements. Two of them are J. Locke and L. Wittgenstein. They have been quite critical of the statements in question. Still, they have not quite been successful at explaining why people make such statements all the time. How is it possible that so 
many people engage in so much futility all the time?

J. Locke devotes a chapter to the statements in question entitled "Of Trifling Propositions" in his celebrated "An Essay Concerning Human Understanding" [10]. He not only calls them "trifling propositions" but also "identical propositions". He states the following about such prepositions [11].

I know there are some who, because identical propositions are self-evident, show a great concern for them and think they do great service to philosophy by crying them up, as if in them was contained all knowledge, and the understanding were led into all truth by them only. I grant as forwardly as anyone that they are all true and self-evident. I grant further that the foundation of all our knowledge lies in the faculty we have of perceiving the same idea to be the same, and of discerning it from those that are different... But how that vindicates the making use of identical propositions for the improvement of knowledge from the imputation of trifling, I do not see. Let anyone repeat as often as he pleases that The will is the will, or lay what stress on it he thinks fit. of what use is this, and infinite the like propositions, for the enlarging our knowledge? ... [ W]ill these and the like ever help him to an acquaintance with ethics, or instruct him or others in the knowledge of morality? ... [ W] hat advance do such propositions give in the knowledge of anything necessary or useful for their conduct?

Clearly, J. Locke is struggling mightily with the following contradiction. On the one hand, there is the ubiquity of so-called trifling propositions or identical propositions. On the other hand, there is the impression that they do not add to knowledge. What J. Locke does not really do is try to look for a reason for the existence of the statements in question.

All this gives his discussion a certain unfinished impression. A key question is left dangling. What are identical propositions for? J. Locke professes what they are not for, namely to add to knowledge. But since they exist and are ubiquitous, they do have to exist for some purpose. One likes to think that everything exists for a reason.

J. Locke undertakes no attempt to discover a reason for why identical propositions exist. One is left with the uncomfortable impression that human beings very, very often engage in a completely inane and futile activity when they utter identical propositions. How can this possibly be? J. Locke offers no way out. It has been proposed above that nothing is more fundamental to the human condition than J. Locke's trifling or identical propositions.

G. Boole knew about J. Locke's views and wisely notes the following about the so-called trifling propositions [12].

Regarded as supplanting experience, or as furnishing materials for the vain and wordy janglings of the schools, such propositions are worse than trifling. Viewed, on the other hand, as intimately allied with the very laws and conditions of thought, they rise into at least a speculative importance.

In short, G. Boole sensed that there was something truly fundamental about such propositions. 
L. Wittgenstein's judgment about identical propositions is even more severe. He completely dismisses them in laconic fashion, as follows [13]:

Beiläufig gesprochen: Von zwei Dingen zu sagen, sie seien identisch, ist ein Unsinn, und von Einem zu sagen, es sei identisch mit sich selbst, sagt gar nichts.

"Roughly speaking: to say of two things that they are identical is nonsense, and to say of one thing that it is identical with itself is to say nothing".

How can L. Wittgenstein state that it is not possible to state that two things are identical, as in "John is the teacher"? He presumably means that there is more to John than being a teacher. In that regard, "John" and "the teacher" do not completely overlap. Then how can they be declared to be identical?

It would appear that L. Wittgenstein is making an assumption. He assumes that declaring two entities to be identical must involve assuming that they overlap $100 \%$. Overlapping $100 \%$ would mean that they share every single attribute. I do not believe that this assumption is valid.

Rather, in the physics and mathematics of the brain's OS, the concern is not with all the attributes that certain entities exhibit, but just with two attributes. L. Wittgenstein seems to assume that all attributes are involved. They are not. Only what is stated explicitly is involved. And what is stated is two attributes, no more.

In the statement "John is the teacher", the two attributes involved are "John" and "the teacher". All that the statement conveys about the entity or entities exhibiting the property "John" that correspond(s) to the attribute "John" in the brain and the entity or entities exhibiting the property "the teacher" that correspond(s) to the entity "the teacher" in the brain is that they are the same entity or entities. No other attributes than "John" or "the teacher" are involved in this statement. It is otherwise clear that the entities in question have attributes other than "John" and "the teacher".

L. Wittgenstein sidesteps the question as to why people, as he assumes, incessantly either talk nonsense or say absolutely nothing. I rather represent the opposite view, according to which all statements uttered by people do make sense, including the ones that seem to say nothing. I simply refuse to accept that so many people could so often babble nonsense.

J. Locke and L. Wittgenstein refuse, it would seem, to endow any meaning to what J. Locke calls trifling propositions. I personally hold quite the contrary opinion. I take my point of departure from the fact that trifling propositions are an undeniable fact of human intelligence. The empirical evidence is totally overwhelming. The propositions in question are ubiquitous.

It appears to me, as opposed to J. Locke and L. Wittgenstein, that the statements reveal a deep and fundamental characteristic about how the brain experiences what is outside itself in terms of rational human intelligence. I might even add that there is no characteristic-so it seems to me-that is more deeply characteristic of, or more fundamental to, rational human intelligence. Every minute spent reflecting on it is a minute well spent. 
The characteristic in question may be called digital in the sense that it involves a contrast between two states. It is this characteristic that makes rational human intelligence fundamentally digital.

It is also this same characteristic, I believe, that lies at the foundation of anything that has been called a fundamental law of thought or axiom of thought. Aristotle appears to have assumed that there is only one fundamental law of thought, even if he formulates it in more than one way (see above). But as was seen above, there has been a tendency to distinguish, after Aristotle, between three axioms of thought. It is my firm belief that all that has ever been defined as a fundamental law of thought is an effort to give expression to the single same most fundamental characteristic of rational human intelligence.

\section{Conclusions}

In the months and years after the afore-mentioned 2015 book was completed, a number of issues arose that seemed in need of further clarification. There are four. They have been updated in the present article, which is for all practical purposes an appendix to the book.

The first issue is the traditional laws of thought, discussed endlessly over more than 2000 years. If the theory of the brain's OS is complete, then what to make of these laws? The present article establishes the exact relation of the laws to the complete theory in strictly mathematical terms.

The second issue concerns the number of digitalities that make up the brain's OS. In the book, there were five (5). But further examination revealed the necessity for adding a sixth to make the model complete. It is defined in the present article.

The third issue concerns the proposal that the theory of the brain's OS is both physical and mathematical. Theories of physics have laws. Mathematics has axioms. The theory of the brain's OS therefore ought to have both. The present article clarifies this critical distinction.

The fourth issue is the problem that the theory of the brain's OS says nothing about the true causes, the activity of neurons in the brain. But even theories of the physics of matter and motion do not really say what mass and space and time are. It is therefore necessary to use one's imagination in new ways. Examples are adduced of theories of physics that do not directly describe what is happening.

\section{Acknowledgements}

I thank three anonymous referees for their contributions, which I believe have much improved the present article.

\section{Conflicts of Interest}

The author declares no conflicts of interest regarding the publication of this paper. 


\section{References}

[1] Depuydt, L. (2015) Prolegomena to the Complete Physical and a Mathematical Theory of Rational Human Intelligence in Boolean, Lagrangian, and Maxwellian Mode. Science Research Publishing.

[2] Kolmogorov, A.N. (1967) On the Principle of Excluded Middle. In: van Heijenoort, J., Ed., From Frege to Gödel: A Source Book in Mathematical Logic, 1879-1931, Harvard University Press, Cambridge, Massachusetts, 416-437.

[3] Brouwer, L.E.J. (1967) On the Significance of the Principle of Excluded Middle in Mathematics, Especially in Function Theory. In: van Heijenoort, J., Ed., From Frege to Gödel: A Source Book in Mathematical Logic, 1879-1931, Harvard University Press, Cambridge, Massachusetts, 334-345.

[4] Depuydt, L. (2008) The Other Mathematics: Language and Logic in Egyptian and General. Gorgias Press, Piscataway, NJ. https://doi.org/10.31826/9781463211356

[5] Aristotle, Metaphysics Books I-IX," with an English translation by H. Tredennick, Loeb Classical Library, 271, Harvard University, Cambridge Massachusetts, 1933, pp. 160 (citation 1 in section iii. 9 of Book IV), 162 (citation 2 in section iii.12 and citation 3 in section iv.1), and 198 (citation 4 in section vi.10). It is now standard practice to locate passages in Aristotle according to the page and the column, and sometimes also the lines, in I. Bekker's epochal edition of Aristotle (1831-1870). Citations 1 and 2 are found in 1005b, citation 3 in 1010b, and citation 4 in 1011b.

[6] Metaphysics IV.iv.2.

[7] de Strycker, E. (1967) Beknopte geschiedenis van de antieke filosofie [Succinct History of Ancient Philosophy]. Uitgeverij de Nederlandsche Boekhandel, Antwerp, 103.

[8] Leibniz, G.W. (1959) Opera Philosophica Quae Extant Latina Gallica Germanica Omnia. Scientia, Aalen (facsimile of the original edition of 1840 by J. E. Erdmann, supplemented with additional texts and a preface by R. Vollbrecht), 339, 515 Section 44.

[9] Boole, G. (1854) An Investigation of the Laws of Thought, on Which Are Founded the Mathematical Theories of Logic and Probabilities. Walton and Maberly, London, 240. https://doi.org/10.5962/bhl.title.29413

[10] Locke, J. (1961) An Essay Concerning Human Understanding. Everyman's Library, 984, Philosophy, J. M. Dent \& Sons Ltd., London, and E. P. Dutton \& Co Inc., New York.

[11] Locke, J. (1961) An Essay Concerning Human Understanding. Everyman's Library, 984, Philosophy, J. M. Dent \& Sons Ltd., London, and E. P. Dutton \& Co Inc., New York, 209-210.

[12] Boole, G. (1854) An Investigation of the Laws of Thought, on Which Are Founded the Mathematical Theories of Logic and Probabilities. Walton and Maberly, London, 184. https://doi.org/10.5962/bhl.title.29413

[13] Wittgenstein, L. (1992) Tractatus Logico-Philosophicus. B. Russell, Brace \& Company, Inc., New York, and Kegan Paul, Trench, Trubner \& Co. Ltd., London, 138-139. 